\title{
Size-resolved aerosol composition at an urban and a rural site in the Po Valley in summertime: implications for secondary aerosol formation
}

\author{
Silvia Sandrini ${ }^{1}$, Dominik van Pinxteren ${ }^{2}$, Lara Giulianelli $^{1}$, Hartmut Herrmann ${ }^{2}$, Laurent Poulain $^{2}$, \\ Maria Cristina Facchini ${ }^{1}$, Stefania Gilardoni ${ }^{1}$, Matteo Rinaldi ${ }^{1}$, Marco Paglione ${ }^{1}$, Barbara J. Turpin ${ }^{3}$, \\ Francesca Pollini ${ }^{1}$, Silvia Bucci ${ }^{4,5}$, Nicola Zanca ${ }^{1}$, and Stefano Decesari ${ }^{1}$ \\ ${ }^{1}$ Institute for Atmospheric Sciences and Climate (ISAC), National Research Council (CNR), Bologna, 40129, Italy \\ ${ }^{2}$ Leibniz-Institut für Troposphärenforschung (TROPOS), Leipzig, 04318, Germany \\ ${ }^{3}$ Environmental Science and Engineering, Gillings School of Global Public Health, University of North Carolina at Chapel \\ Hill, NC 27599-7431, USA \\ ${ }^{4}$ Institute for Atmospheric Sciences and Climate (ISAC), National Research Council (CNR), Rome, 00133, Italy \\ ${ }^{5}$ Dept. of Physics, Ferrara University, Ferrara, 44121, Italy
}

Correspondence to: Silvia Sandrini (s.sandrini@isac.cnr.it)

Received: 21 December 2015 - Published in Atmos. Chem. Phys. Discuss.: 1 March 2016

Revised: 20 July 2016 - Accepted: 22 July 2016 - Published: 1 September 2016

\begin{abstract}
The aerosol size-segregated chemical composition was analyzed at an urban (Bologna) and a rural (San Pietro Capofiume) site in the Po Valley, Italy, during June and July 2012, by ion-chromatography (major water-soluble ions and organic acids) and evolved gas analysis (total and water-soluble carbon), to investigate sources and mechanisms of secondary aerosol formation during the summer. A significant enhancement of secondary organic and inorganic aerosol mass was observed under anticyclonic conditions with recirculation of planetary boundary layer air but with substantial differences between the urban and the rural site. The data analysis, including a principal component analysis (PCA) on the size-resolved dataset of chemical concentrations, indicated that the photochemical oxidation of inorganic and organic gaseous precursors was an important mechanism of secondary aerosol formation at both sites. In addition, at the rural site a second formation process, explaining the largest fraction (22\%) of the total variance, was active at nighttime, especially under stagnant conditions. Nocturnal chemistry in the rural Po Valley was associated with the formation of ammonium nitrate in large accumulation-mode $(0.42-1.2 \mu \mathrm{m})$ aerosols favored by local thermodynamic conditions (higher relative humidity and lower temperature compared to the urban site). Nocturnal concentrations of fine nitrate were, in fact, on average 5 times
\end{abstract}

higher at the rural site than in Bologna. The water uptake by this highly hygroscopic compound under high RH conditions provided the medium for increased nocturnal aerosol uptake of water-soluble organic gases and possibly also for aqueous chemistry, as revealed by the shifting of peak concentrations of secondary compounds (water-soluble organic carbon (WSOC) and sulfate) toward the large accumulation mode $(0.42-1.2 \mu \mathrm{m})$. Contrarily, the diurnal production of WSOC (proxy for secondary organic aerosol) by photochemistry was similar at the two sites but mostly affected the small accumulation mode of particles $(0.14-0.42 \mu \mathrm{m})$ in Bologna, while a shift to larger accumulation mode was observed at the rural site. A significant increment in carbonaceous aerosol concentration (for both WSOC and water-insoluble carbon) at the urban site was recorded mainly in the quasi-ultrafine fraction (size range $0.05-0.14 \mu \mathrm{m}$ ), indicating a direct influence of traffic emissions on the mass concentrations of this range of particles. 


\section{Introduction}

The knowledge of the size-segregated chemical composition of atmospheric aerosols, i.e., the chemical composition as a function of particle size, is key to the understanding of several important characteristics of particles such as optical properties, hygroscopicity and reactivity, which affect the atmospheric radiation budget, cloud formation and human health. Moreover, the size distribution of inorganic and organic components reflects their origin, and hence provides a wealth of information about aerosol formation mechanisms and atmospheric processing, including secondary formation (Seinfeld and Pandis, 1998).

Accumulation-mode particulate matter mostly originates from aerosol accretion via gas-to-particle conversion of oxidized vapors (Seinfeld and Pandis, 1998). However, accumulation-mode particles can be selectively scavenged by clouds and fogs which, in absence of precipitation, produce chemically processed particles upon evaporation of water (Meng and Seinfeld, 1994). The resulting size distribution is bimodal with the small mode accounting for secondary aerosols produced uniquely by gas-to-particle conversion ("condensation mode") and the large mode containing particles that underwent cloud processing ("droplet mode") (Hering and Friedlander, 1982; John et al., 1990). Therefore, knowledge about the concentrations of aerosol organic and inorganic compounds in size-segregated aerosol samples provides information on the nature of secondary formation processes. Measurements of the size-segregated chemical composition of aerosols are traditionally performed using multi-stage impactors followed by offline chemical analysis. Recently, the development of online mass spectrometric techniques offered new opportunities for size-segregated chemical observations with a much greater time resolution with respect to impactors (Jimenez et al., 2003). However, aerosol mass spectrometers (AMSs) generally suffer from poor sensitivity for thermally refractory compounds and could not be deployed for the analysis of coarse particles $(>2.5 \mu \mathrm{m})$ chemical composition. Therefore, multistage impactors are still unsurpassed in terms of the number of chemical determinations that can be performed on the samples and the range of particle sizes that can be probed. An example of comparison of aerosol chemical measurements performed using a five-stage impactor and AMS is provided by our previous study focusing on the 2009 field campaign in the Po Valley, Italy (Decesari et al., 2014).

The Po Valley is a region in Europe characterized by high levels of pollution due to the concurrent high density of anthropogenic sources and its orographic and meteorological characteristics particularly unfavorable for pollutant dispersion. In particular, several studies have shown how this area is dominated by secondary material during the summer (Crosier et al., 2007), with a large presence of secondary inorganic aerosol (SIA). On an annual average, SIA accounts for $40 \%$ of $\mathrm{PM}_{10}$ mass at the urban site of Bologna (Matta et al., 2003; Putaud et al., 2010) while a 50\% contribution has been evaluated at the rural site of San Pietro Capofiume over shorter observation periods during winter and summer (Carbone et al., 2010). Crosier et al. (2007) observed that most of the time, during the summer, aerosol over the Po Valley was composed of regional ammonium sulfate and organic material, while under anticyclonic conditions, with recirculation of air over the region, the composition was dominated by ammonium nitrate close to ammonia emission sources.

The present study focuses on the chemical size-resolved composition of aerosol determined by two five-stage lowpressure Berner impactors during a field campaign performed in the summer 2012 in the Po Valley. With respect to the previous campaigns in this area, this is the first experiment where a two-site approach was used. One-month intensive observations were performed at an urban site (Bologna, BO) and at a nearby rural site (San Pietro Capofiume, SPC). The goal of this paper is to provide insights into factors controlling the variability of aerosol composition and to explore possible formation pathways of secondary compounds in this region during the summer under different meteorological conditions and air-mass history. The two-site approach was adopted to estimate the contribution and composition of rural background particles with respect to the urban contribution, according to the Lenschow perspective (Lenschow et al., 2001), based on the assumption that PM concentration measured at an urban location is the result of the sum of regional background, urban contribution given by the sources inside the agglomeration and road traffic for roadside sites.

Source attribution was addressed through the analysis of the time series of the main aerosol species together with meteorological parameters and by the statistical approach of principal component analysis (PCA) applied to the different size classes as independent variables. The study also takes into account the comparison between an urban and a rural site to assess the impact of traffic and other urban sources on the regional background, to explore differences in secondary aerosol formation resulting from different meteorological conditions and to assess the regional and local variability of secondary aerosol formation processes. Finally, the fact that sampling was performed separately during day and night allowed analysis of the concentrations of aerosol constituents together with the dynamics of the boundary layer (Gietl et al., 2008).

\section{Experimental}

\subsection{Sampling sites}

Size-segregated aerosol sampling was performed during the PEGASOS field campaign in the Po Valley (Italy), from 12 June to 9 July 2012 , at the urban site of BO $\left(44^{\circ} 29^{\prime} \mathrm{N}\right.$, $11^{\circ} 20^{\prime} \mathrm{E} ; 54 \mathrm{~m}$ a.s.l. $)$ and at the rural site of SPC $\left(44^{\circ} 39^{\prime} \mathrm{N}\right.$, $11^{\circ} 37^{\prime} \mathrm{E} ; 11 \mathrm{ma}$ a.s.l.), $30 \mathrm{~km}$ northeast from the city of 
Bologna. Both sites are located in the eastern part of the Po Valley (Fig. 1). Bologna is a city of 400000 inhabitants, the most populous in the southern Po Valley, with a surrounding area characterized by widespread agricultural and industrial activities and by the presence of several high-traffic roads. Sampling was performed in the northern outskirts of Bologna, on the roof of the Institute of Atmospheric Sciences and Climate of the National Research Council, at about $20 \mathrm{~m}$ above ground. San Pietro Capofiume is a rural site characterized by a flat terrain and by croplands extending in all directions and can be considered an ideal receptor site for regional-scale air pollution in the Po Valley. In SPC aerosol samplers were positioned on a platform at about $8 \mathrm{~m}$ above ground level.

The west-east orientation of the valley favors westerly or easterly circulations, hence from either the inner Po Valley (including Lombardy and Milan) or the Adriatic Sea. In the presence of SW winds, SPC can be located downwind of BO and an influence from the urban area cannot be excluded. Under the same conditions, a possible inflow of marine air from the Ligurian Sea is also possible.

\subsection{Aerosol sampling}

Two five-stage Berner impactors (flow rate $80 \mathrm{~L} \mathrm{~min}^{-1}$ ) with $50 \%$ particle cut points at $0.14,0.42,1.2,3.5$ and $10 \mu \mathrm{m}$ aerodynamic diameter (Dp) were used at the two sites. The particles were collected on aluminium and Tedlar foils. Aluminium foils for carbonaceous aerosol analysis were placed on each stage of the impactor with Tedlar half foils for ionchromatographic analysis placed on top of them, covering $50 \%$ of the aluminium substrates (Matta et al., 2003). A $12 \mathrm{~h}$ time resolution was adopted for sampling: one nighttime and one daytime sample collected every day from 21:00 to 09:00 LT and from 09:00 to 21:00 LT respectively. However, it is worth noting that nocturnal sampling actually included several hours of light: from dawn (which in this period of the year occurs at approximately 05:30) to 09:00.

In order to evaluate the presence of sampling artifacts in the Berner impactor sampling, the size-integrated $\left(\mathrm{PM}_{1.2}\right.$, sum of the first three stages) impactor concentrations for sulfate, nitrate and ammonium were compared with those obtained by another offline system, a high-volume Digitel $\mathrm{PM}_{1}$ sampler, and by integrated HR-ToF-AMS $(\mathrm{PM}<1)$ measurements. See Sect. S1 in the Supplement for a detailed discussion.

\subsection{Analytical measurements}

The Tedlar substrates were extracted in $10 \mathrm{~mL}$ of $\mathrm{mQ}$ water for $30 \mathrm{~min}$ in an ultrasonic bath. The extracts were analyzed by ion chromatography for the quantification of watersoluble inorganic species and organic acids (acetate, formate, methanesulfonate (MSA), oxalate). A TOC analyzer (Shimadzu, Japan) was used for the determination of water- soluble organic carbon (WSOC). An aliquot of each sample was analyzed for total carbon (TC) by combustion at $680^{\circ} \mathrm{C}$ in the presence of a catalyst, while another aliquot was acidified in a reaction vessel to determine IC, which was decomposed to $\mathrm{CO}_{2}$. In both cases the evolved $\mathrm{CO}_{2}$ was measured by a nondispersive infrared gas analyzer (NDIR) and the organic fraction (WSOC) was obtained by difference between TC and IC.

Fractions of the aluminium foils were used for the quantification of TC by evolved gas analysis with a Multi N/C2100 analyzer (Analytik Jena, Germany) equipped with a module for solid samples. Portions of the aluminium foils were exposed to increasing temperature (up to $950{ }^{\circ} \mathrm{C}$ ) in pure oxygen carrier gas. Under these conditions all carbonaceous matter (organic, carbonate and elemental carbon, EC) is converted to $\mathrm{CO}_{2}$ (Gelencser et al., 2000) and TC is measured as total evolved $\mathrm{CO}_{2}$ by an NDIR analyzer.

Aluminium foils in SPC were also used for the gravimetric determination of aerosol mass by weighing the substrates before and after sampling on a UMT-2 microbalance with a reading precision of $0.1 \mu \mathrm{g}$ and a standard deviation of ca. $1 \%$.

\subsection{Back-trajectory calculation}

Air-mass back trajectories are a useful tool when studying the aerosol composition as a function of the air-mass history. For every hour during each sampling interval (12 h during night and $12 \mathrm{~h}$ during day), $96 \mathrm{~h}$ back trajectories arriving at 500 ma.g.l. were calculated by the HYSPLIT model (HYbrid Single-Particle Lagrangian Integrated Trajectory, version 4) (Draxler and Rolph, 2003) in the ensemble mode, using input field from the global $1^{\circ}$ GDAS archive (http: www.arl.noaa.gov/ss/transport/archives.html). Ensembles of 27 trajectories for a given starting time for all possible offsets in $X, Y$ and $Z$ dimensions (ca. $250 \mathrm{~m}$ offset in $Z$, one grid cell offset in $X$ and $Y$ ) were calculated for every hour, resulting in a total of 324 trajectories describing the air-mass history of each $12 \mathrm{~h}$ sample. In addition to the endpoints of the trajectories, other HYSPLIT output parameters (sun flux, mixing layer depth) were stored and averaged along the trajectories (sun flux) and at the receptor site (sun flux and mixing layer depth) during the sampling intervals. Even though the mixing layer height provided by the HYSPLIT model might be quite inaccurate, the trend of this parameter was taken as a proxy of the boundary layer dynamics for the campaign. In addition, residence time indices (RTIs) were calculated by GIS analysis, reflecting the time the sampled air masses resided above certain land cover categories (water, natural vegetation, agricultural lands, bare areas and urban areas). Details of this method are given in van Pinxteren et al. (2010). 


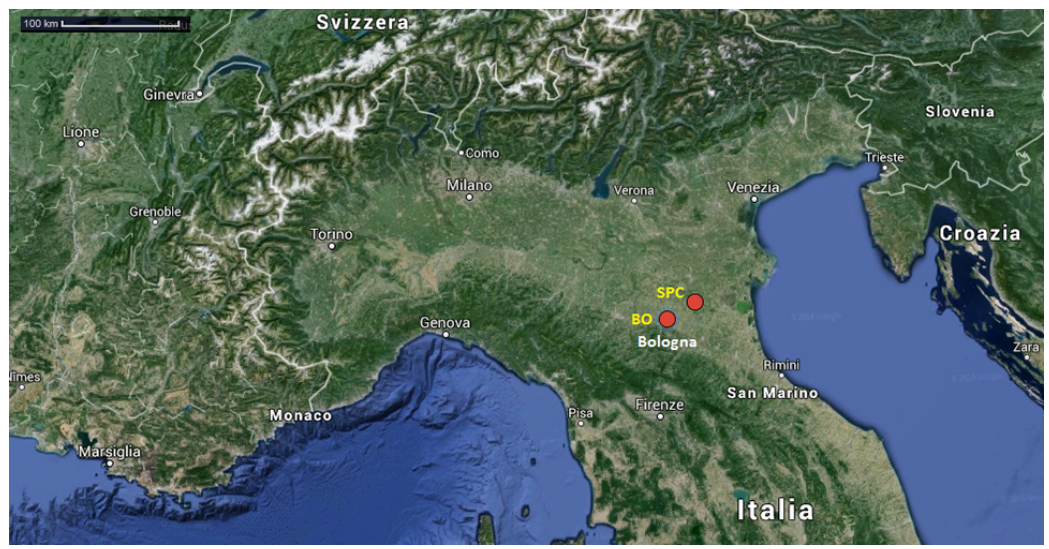

Figure 1. Location of the sampling sites in the Po Valley.

\subsection{Aerosol liquid water content (ALWC) calculation}

Hourly ALWC was calculated by the online version of the Extended Aerosol Inorganic Model III (E-AIM, http://www. aim.env.uea.ac.uk/aim/aim.php; Clegg et al., 1998; Wexler and Clegg, 2002). The inorganic concentrations for sulfate, ammonium, nitrate and chloride measured by two HR-ToFAMSs, placed in $\mathrm{BO}$ and in SPC during the campaign, were used as inputs in conjunction with $\mathrm{RH}$, while temperature was kept fixed at $298.15 \mathrm{~K}$ by this model. Sodium was not measured by AMS and it is here ignored in the calculation. Sodium represents only $2 \%$ of the total equivalents of total ionic species used as inputs of E-AIM, on the basis of the impactor composition. The size-segregated concentrations of the inorganic components collected by the Berner impactors could not be used for this purpose due to their low temporal resolution $(12 \mathrm{~h})$, resulting in a flattening of $\mathrm{RH}$ values averaged over the sampling time, which prevented accurate calculation of ALWC on particles. Particulate water retained by polar organic matter was neglected in the calculations, because the inclusion of ionic organic compounds (oxalic, glutaric and maleic carboxylic acids) had been shown to play only a minor role in water uptake during the campaign (Hodas et al., 2014). The formation of solids was allowed in the model because in the absence of hygroscopicity measurements it was not possible to know whether aerosols effloresced or not in this environment. The ALWC calculated from AMS relates to the fine fraction $(<1 \mu \mathrm{m}$ diameter $)$ of aerosol.

\subsection{Principal component analysis}

Source categories for the five impactor size intervals of particulate matter were studied by means of PCA using the XLStat software (Addinsoft, version 2013.2.04). Besides the concentrations of particle constituents chloride, sulfate, nitrate, sodium, ammonium, magnesium, calcium and WSOC, the database for PCA also included the modeled meteorolog- ical parameters from the HYSPLIT model listed in the previous section, the measured meteorological parameters temperature and relative humidity (RH) and the modeled residence times from GIS analysis.

The values below detection limits were replaced by half the respective value of detection limit (Farnham et al., 2002) in the final dataset.

Since a prerequisite of PCA is the normal distribution of the variables used in the analysis, the normal distribution of concentration data has been checked by the Shapiro-Wilk normality test. Data that were not normally distributed were $\log -10$ transformed before the analysis.

The orthogonal transformation method with Varimax rotation of principal components was applied to redistribute the variance in order to generate more interpretable factor loadings and scores (Vandeginste, 1998). As there are no defined criteria for the number of factors which are used in the Varimax rotation, we performed several PCAs with varying numbers of rotated factors (4-9) and judged the interpretability of the results by trying to assign a physical meaning to the extracted factors. The number of rotated factors was regarded as too high if factors showed very low contribution to the overall variance and no distinct physical meaning. Contrarily the number was regarded too low if previously resolved sources were now folded into one principal component. The most reasonable results were obtained by rotating the first six factors.

\section{Results}

\subsection{Back-trajectory patterns}

The PEGASOS summer campaign was characterized by the occurrence of different meteorological patterns, with the first part characterized by days of very perturbed weather followed by stable anticyclonic conditions and the second part experiencing more variable meteorological conditions. During the study period, weak westerly breezes affected the sam- 
pling sites at night and in the morning hours, while short, intense easterly breezes dominated during the late afternoon (Fig. 2 in Wolf et al., 2015). However, in days of stronger synoptic forcing, a wind pattern characterized by strong easterly winds, persisting all day, was observed (especially in the second half of June), while a wind pattern characterized by SW winds from the Apennines was also common in June and accounted for most of the days in July until the end of the campaign. An overview of the main air-mass transport patterns intersecting the area during the campaign, from backtrajectory analysis, is reported in a parallel paper (Decesari et al., 2016). A hierarchical cluster analysis (Dorling et al., 1992) of the obtained back trajectories was performed to reduce the number of "origins of air masses", appointing every calculated individual back trajectory to the most appropriate cluster, roughly corresponding to a specific synoptic situation. At each step of the process, the appropriate number of clusters was selected by looking at the variations of the total spatial variance (TSV - defined as the sum of the squared distances between the endpoints of the single trajectory and the mean of the trajectories in that cluster). The optimum number of clusters was selected in correspondence with the number after which the TSV did not vary substantially. The analysis led to identification of five main patterns affecting the Po Valley during the experimental campaign. A map with the mean trajectories for each cluster and the corresponding percentage of occurrence for trajectories calculated over $96 \mathrm{~h}$ and arriving at $500 \mathrm{~m}$ a.g.l. is shown in Fig. 2.

Clusters 1 and 3, defined, respectively, as "WEST low" and "EAST low" according to their low traveling altitude (below $1000 \mathrm{~m}$ a.g.l.) and prevalent direction, were characterized by short trajectory lengths and corresponded to a higher residence time of air masses in the basin. Cluster 1, in particular, had the highest occurrence and accounted for $38 \%$ of the total trajectories. Both included a smaller number of very short trajectories which were defined as "WEST-low local" and "EAST-low local", occurring during the days characterized by stagnant conditions and low wind speed, and were associated with the accumulation of pollutants.

Under stagnant conditions weak winds were accompanied by a shallower boundary layer, as observed from lidar measurements and from radiosoundings in SPC (see Supplement, Fig. S1). The planetary boundary layer (PBL) was around $1000 \mathrm{~m}$ or lower at noon under stagnant conditions, compared to $1600-1700 \mathrm{~m}$ observed during other periods of the campaign at the same hour of the day.

\subsection{Bulk $\mathrm{PM}_{10}$ aerosol composition}

The size cut between fine and coarse particles in the Berner impactor size distributions is set to a $1.2 \mu \mathrm{m}$ aerodynamic diameter (i.e., the size cut between the third and the fourth impactor stage); therefore in this study $\mathrm{PM}_{1.2}$ and $\mathrm{PM}_{1.2-10}$ represent the fine and the coarse aerosol fractions respectively. Figure 3 shows the time series of $\mathrm{PM}_{1.2}$ and $\mathrm{PM}_{1.2-10}$

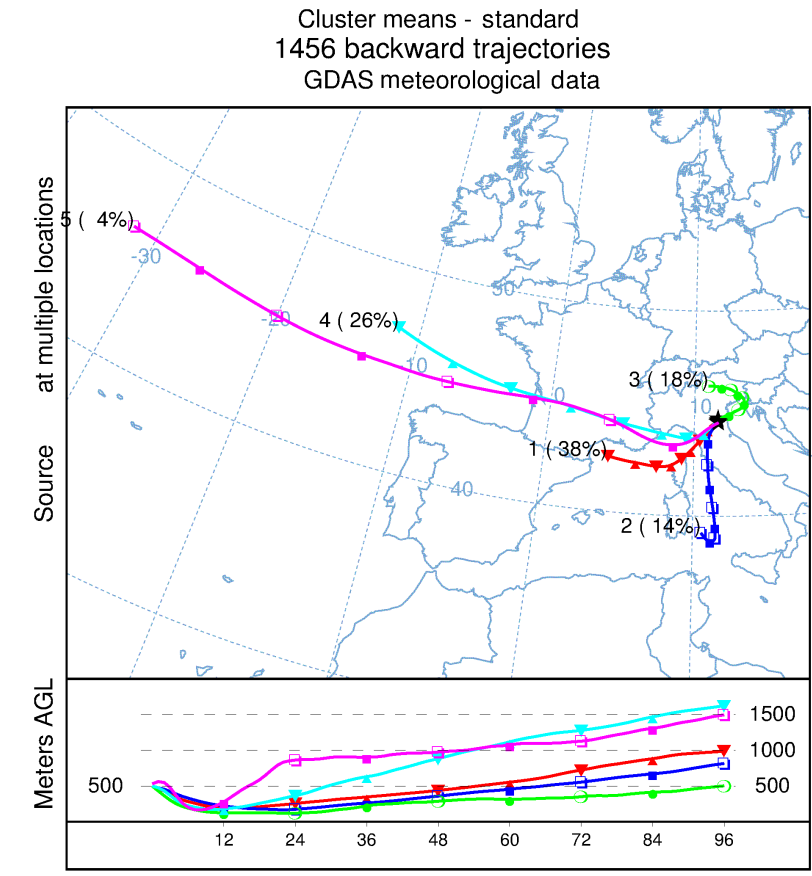

Figure 2. Map with average trajectories for each obtained cluster with, in brackets, corresponding percentage of occurrence. The numbers outside the brackets identify each cluster. Figure refers to $96 \mathrm{~h}$ trajectories arriving at $500 \mathrm{~m}$ a.g.l.

mass concentrations and of the contribution of $\mathrm{PM}_{1.2}$ on total $\mathrm{PM}_{10}$ for the rural site SPC, together with air-mass categories and back-trajectory length. The aerosol mass was not available for BO. Air-mass categories indicate the prevalent direction of air masses during each sampling day.

During the campaign, the days showing the lowest aerosol mass concentrations were characterized by the longest trajectories, which corresponded to air masses transported over long range from the North Atlantic Ocean (WEST) at the beginning and at the end of the sampling period. The aerosol mass increased from 15 to 18 June, with an enhanced contribution of the $\mathrm{PM}_{1.2}$ fraction to the total $\mathrm{PM}_{10}$, together with a sharp decrease of the trajectories length, following the onset of an anticyclonic period with low wind and air stagnation over the Po Valley. An episode of Saharan dust transport was observed during a period of air transport from south, starting on 19 June at $5 \mathrm{~km}$ height with maximum on 20 June when it reached the PBL, resulting in an increase of $\mathrm{PM}_{10}$ mass at ground level (Bucci et al., 2016). The highest contributions of $\mathrm{PM}_{1.2}$ to $\mathrm{PM}_{10}$ were observed most of the times when 4 -day trajectories were very short $(<1500 \mathrm{~km})$. During the first, persistent stagnation period, lasting from 16 to 19 June, the $\mathrm{PM}_{1.2}$ contribution to $\mathrm{PM}_{10}$ was the highest, with maxima during the night, peaking at $67 \%$ of total $\mathrm{PM}_{10}$ mass on 17 June.

Table 1 lists the concentrations of the aerosol chemical constituents, separately for $\mathrm{PM}_{1.2}$ and $\mathrm{PM}_{1.2-10}$ fractions 

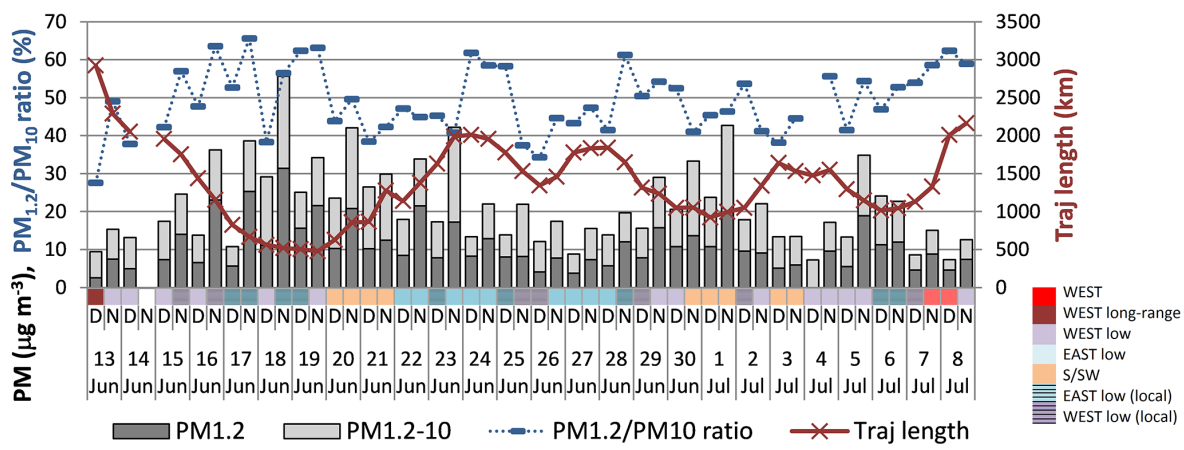

Figure 3. Time series of $\mathrm{PM}_{1.2}$ and $\mathrm{PM}_{10}$ mass concentrations (in $\mu \mathrm{g} \mathrm{m}{ }^{-3}$ ) and of the $\mathrm{PM}_{1.2}$ to $\mathrm{PM}_{10}$ ratio (\%) for SPC. Four-day (96h) back-trajectory length $(\mathrm{km})$ is plotted superimposed to the graph, while air-mass classification (in colors) is reported on top of it. The samples are labeled according to collection starting date, with " $\mathrm{D}$ " and " $\mathrm{N}$ " denoting, respectively, daytime and nighttime samples.

Table 1. Fine $\left(\mathrm{PM}_{1.2}\right)$, coarse $\left(\mathrm{PM}_{1.2-10}\right)$ and $\mathrm{PM}_{10}$ mean concentrations (in $\mu \mathrm{g} \mathrm{m}{ }^{-3}$, from integrated impactor mass size distributions) for main inorganic ions, water-soluble organic carbon (WSOC) and total carbon (TC) separately for day (D) and night (N) samples during the PEGASOS summer campaign.

\begin{tabular}{|c|c|c|c|c|c|c|c|c|c|c|c|c|}
\hline & \multicolumn{4}{|c|}{$\mathrm{PM}_{1.2}$} & \multicolumn{4}{|c|}{$\mathrm{PM}_{1.2-10}$} & \multicolumn{4}{|c|}{$\mathrm{PM}_{10}$} \\
\hline & \multicolumn{2}{|c|}{ BO (urban) } & \multicolumn{2}{|c|}{ SPC (rural) } & \multicolumn{2}{|c|}{ BO (urban) } & \multicolumn{2}{|c|}{ SPC (rural) } & \multicolumn{2}{|c|}{ BO (urban) } & \multicolumn{2}{|c|}{ SPC (rural) } \\
\hline & $\mathrm{D}$ & $\mathrm{N}$ & D & $\mathrm{N}$ & $\mathrm{D}$ & $\mathrm{N}$ & $\mathrm{D}$ & $\mathrm{N}$ & $\mathrm{D}$ & $\mathrm{N}$ & $\mathrm{D}$ & $\mathrm{N}$ \\
\hline Sulfate & 2.1 & 2.6 & 1.7 & 2.3 & 0.27 & 0.32 & 0.16 & 0.28 & 2.3 & 2.8 & 1.8 & 2.6 \\
\hline Nitrate & 0.24 & 0.47 & 0.32 & 2.4 & 1.6 & 1.7 & 0.85 & 1.5 & 1.8 & 2.1 & 1.2 & 3.9 \\
\hline Chloride & 0.023 & 0.043 & 0.0047 & 0.041 & 0.17 & 0.27 & 0.053 & 0.14 & 0.13 & 0.27 & 0.058 & 0.19 \\
\hline Ammonium & 0.83 & 1.1 & 0.69 & 1.5 & 0.055 & 0.068 & 0.021 & 0.15 & 0.88 & 1.1 & 0.69 & 1.6 \\
\hline Magnesium & 0.0077 & 0.0089 & 0.0070 & 0.0064 & 0.069 & 0.073 & 0.038 & 0.045 & 0.066 & 0.081 & 0.045 & 0.051 \\
\hline Calcium & 0.073 & 0.067 & 0.064 & 0.073 & 0.50 & 0.48 & 0.35 & 0.41 & 0.56 & 0.53 & 0.40 & 0.47 \\
\hline Sodium & 0.040 & 0.051 & 0.026 & 0.021 & 0.37 & 0.48 & 0.20 & 0.22 & 0.41 & 0.53 & 0.23 & 0.24 \\
\hline WSOC & 1.4 & 1.9 & 0.94 & 1.6 & 0.54 & 0.53 & 0.28 & 0.44 & 1.9 & 2.4 & 1.2 & 2.1 \\
\hline $\mathrm{TC}$ & 2.5 & 3.5 & 1.3 & 2.2 & 1.5 & 1.5 & 0.8 & 1.4 & 4.1 & 5.2 & 2.1 & 3.5 \\
\hline
\end{tabular}

and for day and night samples. All the chemical species concentrations were higher at the urban compared to the rural site but with small differences in most of the cases. The significantly higher concentrations of fine $\mathrm{TC}$ in $\mathrm{BO}$ can result from a higher contribution of EC and organic carbon (OC) from vehicular traffic at the urban site. Coarse-mode $\mathrm{Mg}^{2+}$ and $\mathrm{Ca}^{2+}$ also occurred at higher concentrations at the urban site, suggesting a source from road dust resuspension for these mineral elements. The only exception was represented by the nocturnal concentrations of fine-mode nitrate, on average 5 times higher at SPC compared to $\mathrm{BO}$, and so for the counter-ion ammonium.

The concentrations of many species were higher at night compared to daytime (Table 1). The nocturnal enhancement can be due either to the accumulation of pollutants in a shallow boundary layer or to enhanced formation/emission of specific aerosol species at nighttime. Figure 4 shows the average $\mathrm{PM}_{10}$ composition at the urban and at the rural site separately for day and night, with indication of the percentage contributions of each species on the total mass of the measured compounds. The change in $\mathrm{PM}_{10}$ chemical com- position between day and night at the rural site indicates that the enhanced mean concentrations found at night were not purely an effect of atmospheric dynamics but were impacted by chemical processes that led to the formation of specific aerosol compounds, especially ammonium nitrate, in the dark hours of the day. The lower average nocturnal temperatures $\left(22^{\circ} \mathrm{C}\right.$ vs. $\left.25^{\circ} \mathrm{C}\right)$ and the higher average nocturnal $\mathrm{RH}$ (70\% vs. $48 \%$ ) of SPC with respect to BO probably played an important role.

Water-insoluble carbon (WINC) was calculated as the difference between TC and WSOC (WINC $=$ TC - WSOC) (Matta et al., 2003). In order to obtain the mass of watersoluble organic material and water-insoluble carbonaceous material conversion factors were applied to include elements different from carbon in the organic molecules. Two distinct factors were used, respectively, for the soluble and the insoluble fraction of OC. WSOC was multiplied by 1.9 at the rural site and by 1.7 at the urban site, applying the two factors derived from AMS measurements performed at the two sites during the same campaign (Gilardoni et al., 2014). WINC 

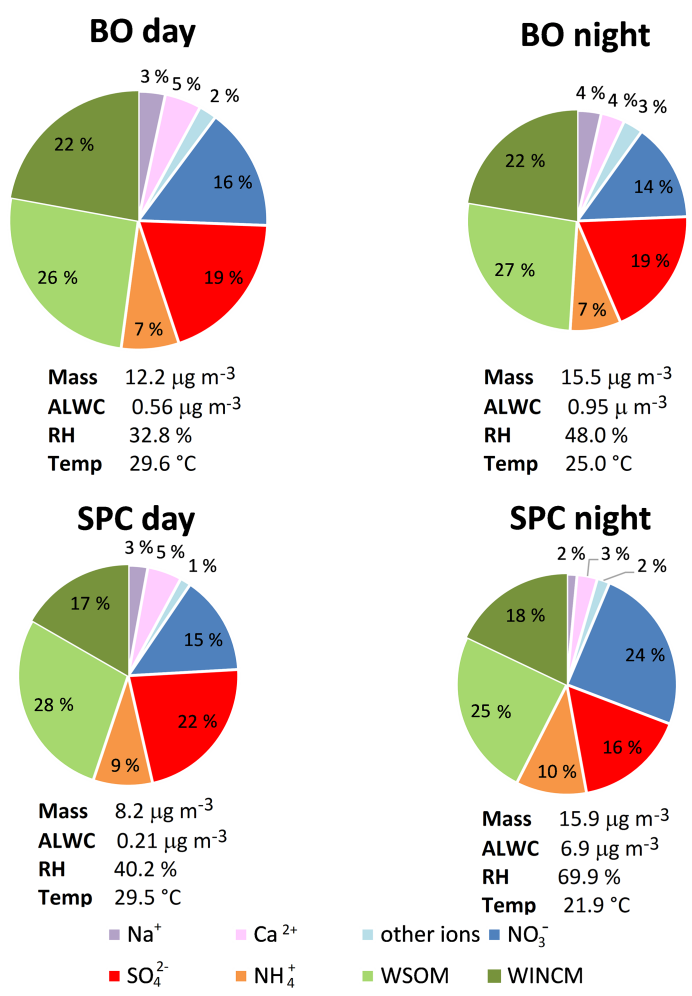

Figure 4. Average day and night $\mathrm{PM}_{10}$ composition at $\mathrm{BO}$ and $\mathrm{SPC}$ during the campaign. "Other ions" include chloride, nitrite, potassium and magnesium. WSOM stands for water-soluble organic matter, while WINCM for water-insoluble carbonaceous matter. Average mass, ALWC, RH and temperature are indicated below each pie. The size of each pie chart is proportional to the total measured mass reported.

was multiplied by 1.2 as found in the literature (Zappoli et al., 1999).

The total mass concentration of the chemical species determined on impactor samples averaged $12.2 \mu \mathrm{g} \mathrm{m}^{-3}$ at the urban and $8.2 \mu \mathrm{g} \mathrm{m}^{-3}$ at the rural site during daytime and 15.1 and 15.9 at nighttime respectively. It is interesting to note that in daytime the aerosol loading was higher at the urban compared to the rural site, indicating a higher contribution from urban sources, though the chemical composition was to some extent homogeneous. By contrast, at night the aerosol mass was similar at the two sites but the chemical composition was different, with an enrichment of ammonium nitrate at the rural site, probably also favored by the high ammonia concentrations from agricultural sources, which during the campaign were only observed at the rural site and not in BO (Sullivan et al., 2015).

The measured mass of $\mathrm{PM}_{10}$ at the urban site consisted on average of 42 and $40 \%$ SIA in daytime and nighttime respectively. At the rural site, SIA represented $46 \%$ in daytime and $50 \%$ at night due to a higher contribution from fine-mode ammonium nitrate. Carbonaceous matter was the dominant fraction at the urban site with 48 and $49 \%$ of the measured mass in daytime and nighttime, respectively, and with the soluble fraction accounting for 26 and $27 \%$ of the mass in the two cases.

Finally, it is worth reminding that the above results are sensitive to sampling artifacts which can affect aerosol collection with low-pressure impactors (e.g., evaporative losses of semivolatile compounds). Figures S8 and S9 report the comparison between SIA measurements with the Berner impactor at SPC and co-located measurements using a different offline system (a HiVol sampler) and an online method (HR-ToF-AMS). The results show that the Berner impactor observations are generally in line with the parallel measurements and especially that the main features of the time trend (e.g., the sharp diurnal variations in nitrate concentrations) are reproduced by all the instruments.

\subsection{Size-resolved aerosol composition}

The time series of size-resolved sulfate, nitrate and WSOC concentrations are shown in Fig. 5 (similar plots for additional chemical components and RH are reported in the Supplement, Figs. S2-S8). The figure highlights significant differences between the urban and the rural site in the formation of secondary inorganic and organic aerosol, especially during the two periods of stagnant conditions, i.e., 16-19 June and 5-7 July, which favored the accumulation of aerosol compounds from local sources. During the first of such events, the sulfate concentrations increased in BO and SPC to a similar extent in daytime, while higher concentrations were measured in SPC at night. Fine-mode nitrate, consisting primarily in ammonium nitrate, was virtually absent during the day throughout the campaign, particularly in $\mathrm{BO}$, as a consequence of the high summer temperatures, which favored the thermal decomposition of $\mathrm{NH}_{4} \mathrm{NO}_{3}$ into gas-phase ammonia and nitric acid. Higher fine-mode nitrate concentrations were instead measured in SPC, reaching high levels at night. For both sulfate and nitrate the most prominent enhancements affected the accumulation mode, i.e., size bins $2(0.14-0.42 \mu \mathrm{m})$ and especially $3(0.42-1.2 \mu \mathrm{m})$ of the impactor, which correspond to small and large accumulation mode.

Aerosol WSOC exhibited higher concentrations under stagnant conditions, similarly to SIAs. During the first stagnation event, in particular, higher nocturnal concentrations in the accumulation mode were measured in SPC compared to $\mathrm{BO}$ (Fig. 5). Conversely, WSOC concentrations were in general higher in BO than in SPC in the quasi-ultrafine $(0.05-0.14 \mu \mathrm{m})$ fraction, with an average concentration of $0.39 \mu \mathrm{g} \mathrm{m}^{-3}$ (17\% of total WSOC in the $\mathrm{PM}_{10}$ fraction) compared to $0.19 \mu \mathrm{g} \mathrm{m}^{-3}$ (11\% of total WSOC in $\mathrm{PM}_{10}$ ). Since secondary formation is believed to represent the major source of WSOC in the absence of biomass burning (Weber et al., 2007), the quasi-ultrafine WSOC excess at the urban site could result from the increased condensation of secondary products on the large surface area of a higher number of very 

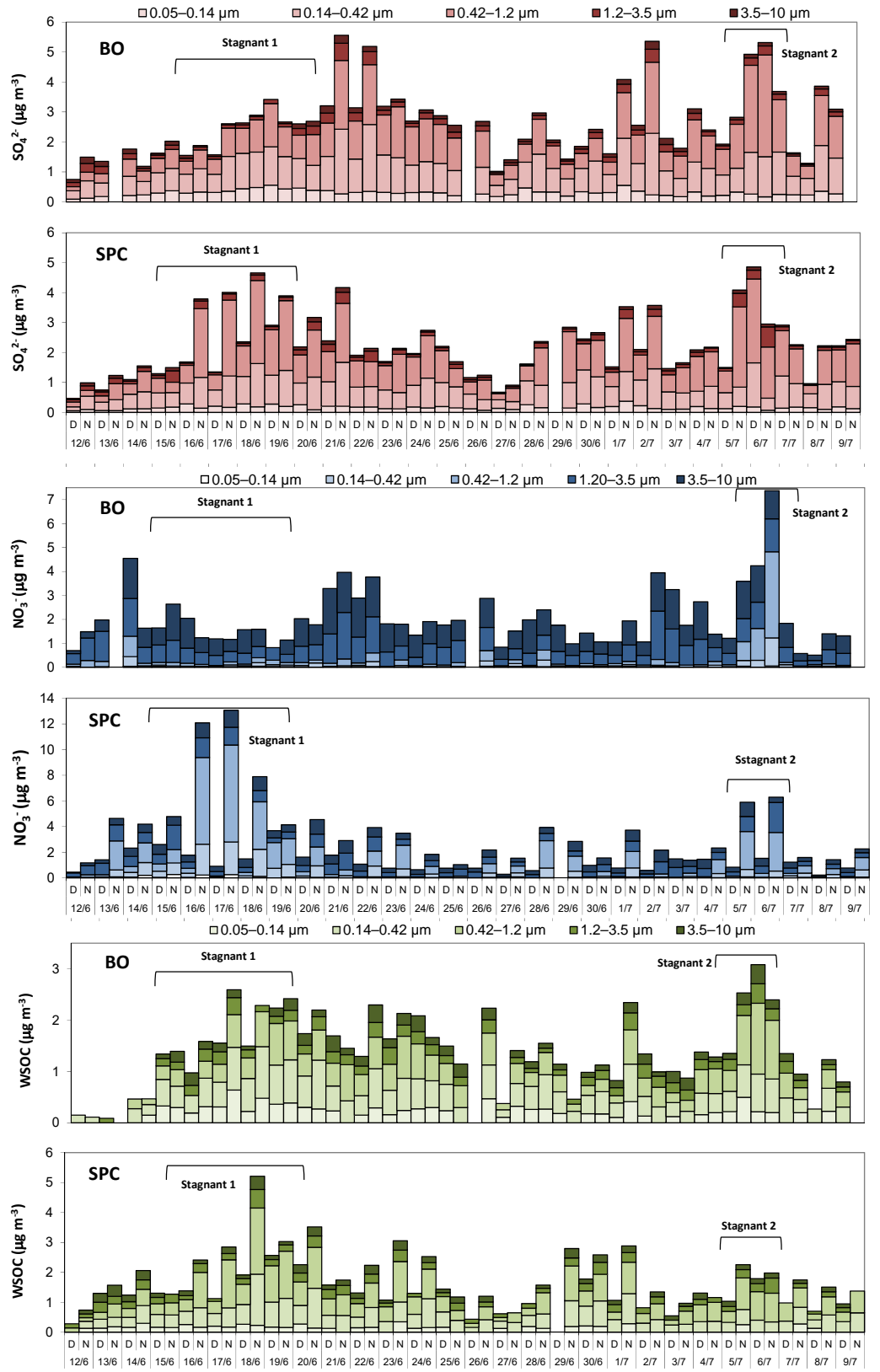

Figure 5. Time series of sulfate, nitrate and WSOC size-segregated concentrations in BO and SPC. Please note the different scale for nitrate and WSOC in BO.

small particles found at the urban site. In addition to freshly nucleated particles, in fact, this aerosol fraction, twice as high in number at urban sites compared to rural areas (Westerdahl et al., 2005), includes particles released by anthropogenic sources such as combustion emissions from vehicular traffic. In addition, this quasi-ultrafine mode excess of WSOC mass could also reflect a direct contribution from anthropogenic primary emissions (Zhang et al., 2012).

On 5 and 6 July, the Po Valley was again influenced by stagnant conditions, with low wind speeds and short air-mass trajectories. However, the stagnation event in early July was considerably shorter than that of 16-19 June. During such event, high concentrations of fine-mode sulfate were simultaneously observed in BO and SPC, with the 6 July experiencing the highest diurnal concentration of the whole campaign $\left(4.9 \mu \mathrm{g} \mathrm{m}^{-3}\right.$ in $\mathrm{PM}_{10}$ in $\left.\mathrm{BO}\right)$. Nitrate similarly increased at both sites at night, persisting in daytime in BO only and reaching the diurnal maximum of $4.2 \mu \mathrm{g} \mathrm{m}^{-3}$ on $\mathrm{PM}_{10}$. Similarly, WSOC increased at both sites, though more significantly in $\mathrm{BO}$, where it reached the highest average diurnal concentration on 6 July. This day was characterized by the highest daytime RH (47.8 and $60.4 \%$ in BO and SPC, re- 
spectively, averaged over the time span of Berner impactor samplings) and a relatively lower temperature $\left(27^{\circ} \mathrm{C}\right.$ at both sites). Clouds were present on the sampling sites and a light rain was recorded in the afternoon. Such conditions apparently favored the formation of secondary organic (WSOC) and inorganic aerosol compounds in the Po Valley basin.

Figure 6 shows the size-segregated concentrations of sulfate, nitrate, ammonium and WSOC during one day characterized by background conditions ( 15 June) and one day characterized by stagnant conditions (18 June), separately for diurnal and nocturnal hours. On the background day (panels a and c), fine particles in $\mathrm{BO}$ exhibited a maximum in the speciated aerosol mass in the small accumulation mode (0.14$0.42 \mu \mathrm{m}$ ), with a relative increase in the large accumulation mode $(0.42-1.2 \mu \mathrm{m})$ at night. The speciated aerosol mass in SPC was almost evenly distributed between the two modes at night and during the day. Nitrate was always present in the coarse mode, where nonvolatile nitrate salts can form through reaction of gaseous nitric acid with alkaline soil particles or resuspended dust (Harrison and Pio, 1983; Laskin et al., 2005). Under stagnant conditions (panels b and d) the speciated particle mass concentrations increased but the peak in the size distribution, which for BO was again observed in the small accumulation mode, shifted to the large accumulation mode in SPC both in daytime and at night. The nocturnal increase of large accumulation-mode particulate matter concentration was much more evident at the rural site (SPC) than at the urban site (BO), mostly because of an increase of ammonium nitrate (showing more than 3 times higher concentrations with respect to background conditions) but also accompanied by increases in WSOC and sulfate concentrations. The SIA mass (i.e., the sum of sulfate, nitrate and ammonium) reached $67 \%$ of the total $\mathrm{PM}_{1.2}$ mass in the night of 16 June, during the first event of stagnation. The increase of SIA (and, to a lesser extent, of WSOC) in large accumulation-mode aerosols under stagnant conditions was therefore the main process modulating the impactor size distribution of submicron aerosol during the experiment. Our data seem to exclude that this shift in diameter of SIAcontaining aerosols from the small to the large accumulationmode size range is due to impactor sampling artifacts (see Sect. S1 in the Supplement, Fig. S11).

\subsection{Secondary aerosol formation under stagnant conditions}

\subsubsection{Secondary inorganic components}

The processes responsible for the accumulation of sulfate, nitrate and secondary organic aerosol (SOA) on stagnation days were further investigated by analyzing the relationship between the (size-segregated) concentrations of secondary inorganic compounds and RH, as well as with ALWC. SPC was characterized by higher levels of RH than Bologna, especially at night. During the campaign RH and temperature profiles at the two sites showed substantial day-night variations as a consequence of diabatic processes at the surface (nocturnal radiative cooling vs. daytime heating from solar irradiation). As a consequence, the highest RH occurred at both sites just before dawn, from 04:00 to 05:00, and the lowest in the afternoon from 13:00 to 15:00. During the diurnal sampling periods (from 09:00 to 21:00) hourly RH ranged from 15 to $66 \%$ in BO and from 19 to $73 \%$ in SPC, while during the nocturnal sampling periods (from 21:00 to 09:00) RH ranged from 24 to $82 \%$ in $\mathrm{BO}$ and from 35 to $92 \%$ in SPC. A plot of RH averaged on the time intervals of the Berner impactor is reported in the Supplement (Fig. S8).

Since the equilibrium constant for the reaction of $\mathrm{NH}_{4} \mathrm{NO}_{3}$ formation is both RH and temperature dependent (Stelson and Seinfeld, 1982), thermodynamic conditions were more favorable in SPC than in BO for the existence of condensedphase nitrate. Both temperature and $\mathrm{RH}$ affect the equilibrium of $\mathrm{NH}_{4} \mathrm{NO}_{3}$, but the changes in $\mathrm{RH}$ were more marked. During the campaign the hourly nocturnal temperatures and corresponding relative humidity of deliquescence (RHD) for ammonium nitrate and ammonium sulfate (in brackets) ranged from $12{ }^{\circ} \mathrm{C}(69.3 \%$ for ammonium nitrate and $80.7 \%$ for ammonium sulfate) to $30^{\circ} \mathrm{C}$ (58.6\% for ammonium nitrate and 79.5 for ammonium sulfate) in SPC and from $16^{\circ} \mathrm{C}(67.1 \%$ for ammonium nitrate and 80.3 for ammonium sulfate) to $30^{\circ} \mathrm{C}$ in $\mathrm{BO}$ (Watson et al., 1994; E-AIM model, http://www.aim.env.uea.ac.uk/aim/ model2/mod2rhw.php). Nocturnal periods of time with RH greater than the RHD of hygroscopic salts were considerably longer in SPC than in BO, and therefore deliquesced particles were common at the rural and very rare at the urban site. This was confirmed by the simultaneous enhancements of the ALWC, calculated from hourly averaged AMS data at the two sites (see the experimental section) by the EAIM model (Fig. 7). While the ALWC in SPC showed a consistent average diurnal trend, with a maximum before dawn when both RH and the concentrations of hygroscopic salts were the highest (Hodas et al., 2014), the diurnal variation in Bologna was less marked, and nighttime ALWC concentrations were 1 order of magnitude smaller than at the rural station (Fig. 7). Considering the Berner impactor sampling periods, ALWC averaged $0.33 \mu \mathrm{g} \mathrm{m}^{-3}$ in daytime in BO (min 0 , max $11.2 \mu \mathrm{g} \mathrm{m}^{-3}$ ) and $0.76 \mu \mathrm{g} \mathrm{m}^{-3}$ at night (min 0 , $\max 16.6 \mu \mathrm{g} \mathrm{m}^{-3}$ ), while in SPC it averaged $0.21 \mu \mathrm{g} \mathrm{m}^{-3}$ during day ( $\min 0, \max 10.4 \mu \mathrm{g} \mathrm{m}^{-3}$ ) and $6.55 \mu \mathrm{g} \mathrm{m}^{-3}$ during night conditions ( $\min 0, \max 59.3 \mu \mathrm{g} \mathrm{m}^{-3}$ ). The $12 \mathrm{~h}$ averaged ALWC data show concentrations increasing rapidly for RH above $60 \%$ (Fig. 8). There is a considerable variability in ALWC levels that must be attributed to the availability of hygroscopic material in the aerosol, as particulate water in subsaturated condition is a function not only of RH but also of the molar concentration of dissolved material in the aerosol.

Figure 8 (panels b, c) shows the relation between nitrate and sulfate concentrations separately in the small accumula- 

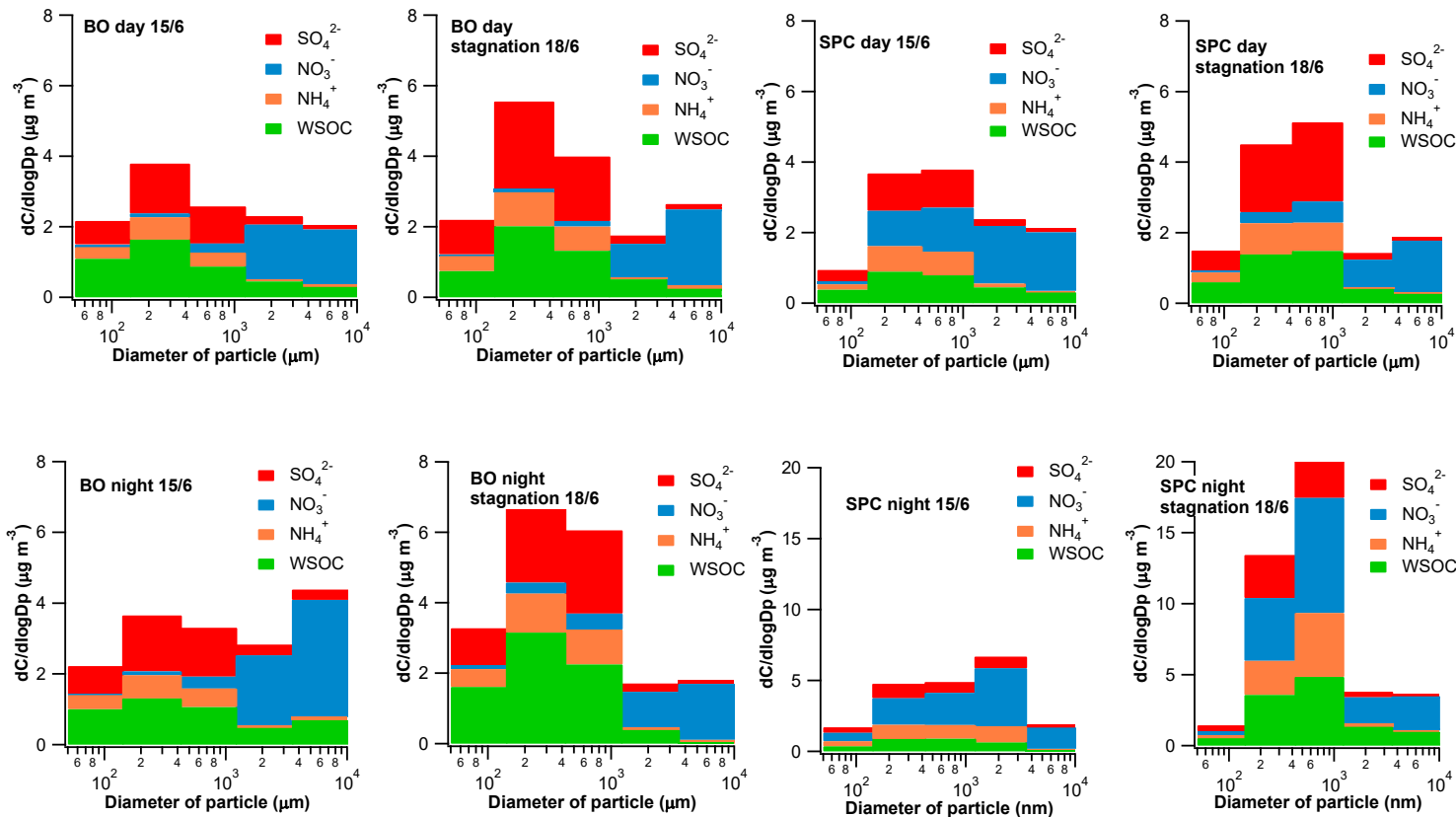

Figure 6. Size-resolved aerosol composition for BO and SPC during day (top) and night (bottom), respectively, during one day characterized by background conditions (15/6) and during one day under stagnant conditions (18/6) (notice the different scale for concentrations in the bottom right panel).

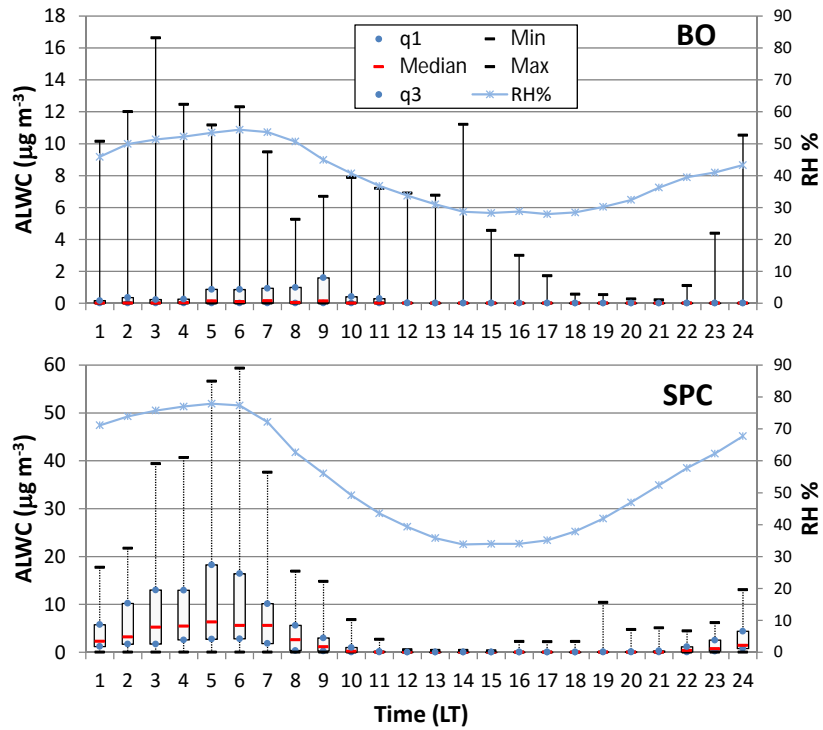

Figure 7. Box plot of average diurnal variation of aerosol liquid water content (ALWC) with superimposed diurnal variation of relative humidity $(\mathrm{RH})$ during the campaign. Please note the different scale of ALWC at the two sites. The labels $\mathrm{q} 1$ and $\mathrm{q} 3$ in the box plot, respectively, denote the first and the third quartiles.

tion mode (condensation mode) and in the large accumulation mode (droplet mode) vs. ALWC for the two sites. The correlation between particulate nitrate and ALWC was strong for both modes in SPC where ALWC levels above $1 \mu \mathrm{g} \mathrm{m}^{-3}$ were frequent.

Our data are in agreement with the findings of Hodas et al. (2014), indicating that particulate nitrate was the primary driver of ALWC observed at night in the rural Po Valley in summertime. The same study suggested that ALWC enhanced the particle-phase partitioning of water-soluble organic gases and provided a medium for aqueous-phase organic reactions that can form SOA. More generally, ALWC can favor - and sometimes can be necessary for - the formation of SOA and SIA in large accumulation-mode aerosols (the droplet mode). Figure 8c shows that no relationship was observed between sulfate and the local estimates of ALWC at either site, with the exception of a moderate positive correlation for the droplet mode in SPC but not in BO. These results indicate that most sulfate was formed at the regional scale during this study (through cloud chemistry in the larger accumulation mode or gas-phase chemistry in the smaller accumulation mode). However, a small but nonzero increment of droplet-mode sulfate concentration in SPC can be attributed to the greater ALWC characterizing the rural site with respect to the urban site.

As a final remark, in this discussion, we attributed the high concentrations of ammonium nitrate at the rural site to the more favorable thermodynamic conditions respect to the urban site. This process was amplified by a positive feedback of ammonium nitrate itself that, by increasing the ALWC in the aerosol phase, further promotes the uptake of precursors $\left(\mathrm{NH}_{3}, \mathrm{HNO}_{3}, \mathrm{~N}_{2} \mathrm{O}_{5}\right)$ from the gas phase (Bertram et al., 

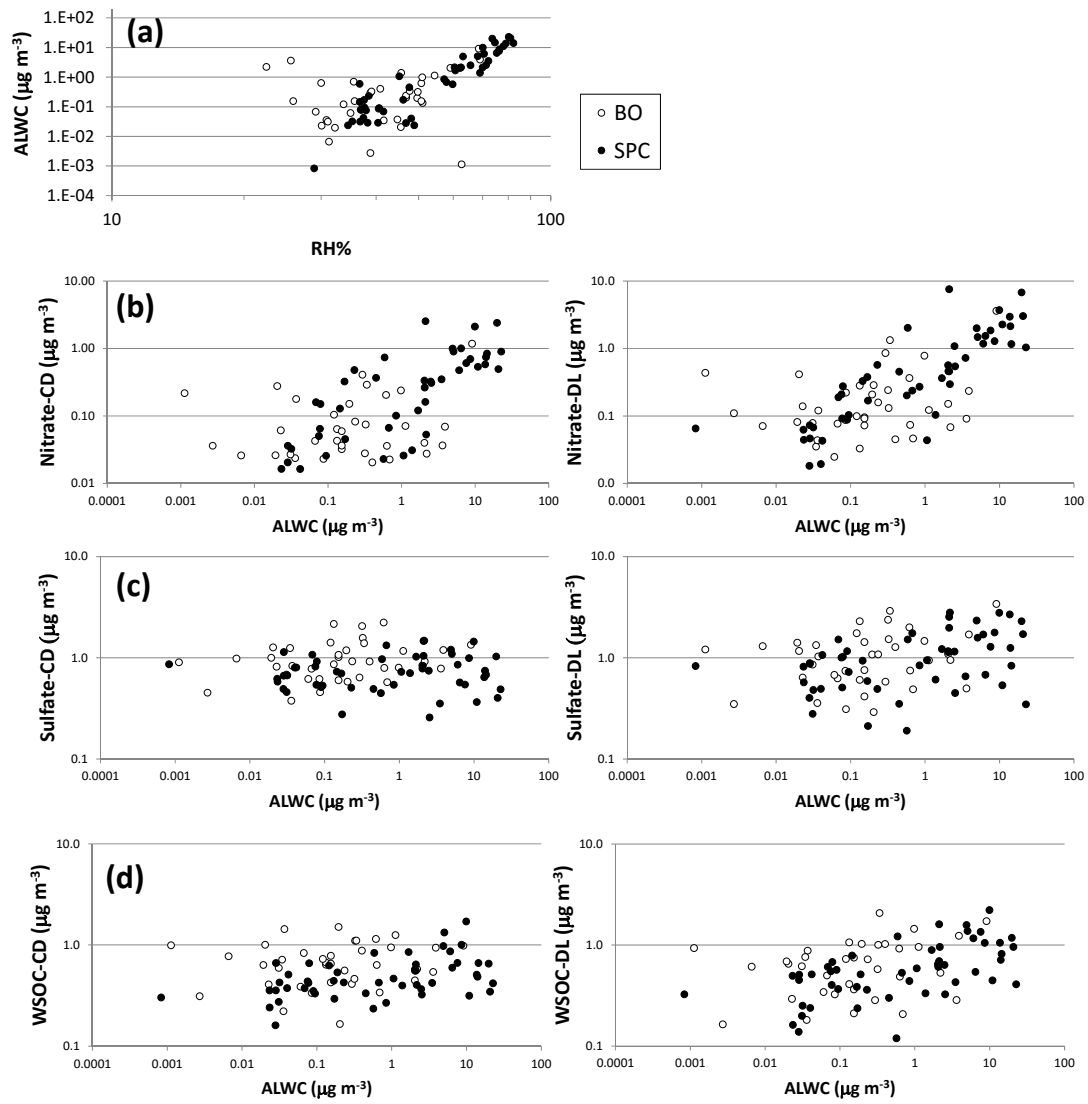

Figure 8. Relationship between ALWC and RH \% (a); relationship between nitrate (b), sulfate (c) and WSOC (d) in the condensation (CD, left panel) and in the droplet (DL, right panel) mode of particles and ALWC averaged over the sampling periods of the Berner impactors.

2009; Schaap et al., 2004). We do not consider here the effect of the different distribution of gaseous precursors of ammonium nitrate in the Po Valley, especially of ammonia, which is enriched in the rural areas (Sullivan et al., 2016), which will be object of a future study.

\subsubsection{Carbonaceous species}

The distribution of the carbonaceous components of aerosol (WSOC, WINC $=$ TC-WSOC) over the Berner impactor size intervals, with emphasis on accumulation-mode particles (condensation and droplet modes), is hereby discussed. The dependence of WSOC on ALWC is also investigated analogously to the case of SIA treated in the previous section.

$\mathrm{PM}_{10}$ WSOC concentrations in this study ranged from 0.13 to $4.6 \mu \mathrm{g} \mathrm{C} \mathrm{m}^{-3}$ (average: $2.1 \mu \mathrm{g} \mathrm{C} \mathrm{m}^{-3}$ ) in BO and from 0.28 to $5.2 \mu \mathrm{g} \mathrm{C} \mathrm{m}^{-3}$ (average: $1.6 \mu \mathrm{g} \mathrm{C} \mathrm{m}^{-3}$ ) in SPC. On average, 79 and $77 \%$ of this $\mathrm{PM}_{10}$ WSOC concentration was in the fine $\left(\mathrm{PM}_{1.2}\right)$ fraction in $\mathrm{BO}$ and SPC, respectively, with only slightly higher contributions at night than in daytime at both sites.

The water-soluble fraction of total carbon (WSOC / TC) in $\mathrm{PM}_{1.2}$ was $52 \%$ on average in $\mathrm{BO}$ and $61 \%$ in SPC. The
WSOC fraction in SPC was comparable to what observed at other rural sites, e.g., $57 \%$ in $\mathrm{PM}_{1}$ in K-puszta (Hungary) during the summer (Krivacsy et al., 2001). The greater watersoluble fraction of carbon found at SPC with respect to BO is in line with literature results, showing higher WSOC fractions in rural areas as a consequence of the concurrent higher input of SOA and the reduced fraction of insoluble carbonaceous particles from traffic sources (Weber et al., 2007).

The left panels in Fig. 9 show the linear regressions of WSOC vs. TC in submicron particles (impactor stages 1 to 3) at the two sites, separately for day and night conditions. At the urban site, a higher slope was observed in daytime $(0.71 \pm 0.10$ at $95 \%$ confidence level $)$ than at nighttime $(0.57 \pm 0.08)$, pointing to the effect of a daytime source for WSOC (consistent with photochemical SOA formation). In daytime, the WSOC fraction of TC in BO overlaps well with that observed in SPC $(0.72 \pm 0.05)$. Contrary to BO, however, WSOC fractions in SPC were similar between night and day $(0.70 \pm 0.07$ at night). Figure 9 shows, in fact, that WSOC and TC occurred in similar proportions in daytime between SPC and BO but with smaller concentrations in SPC (which were therefore "diluted" with respect to BO). In addition, carbonaceous aerosol concentrations increased 

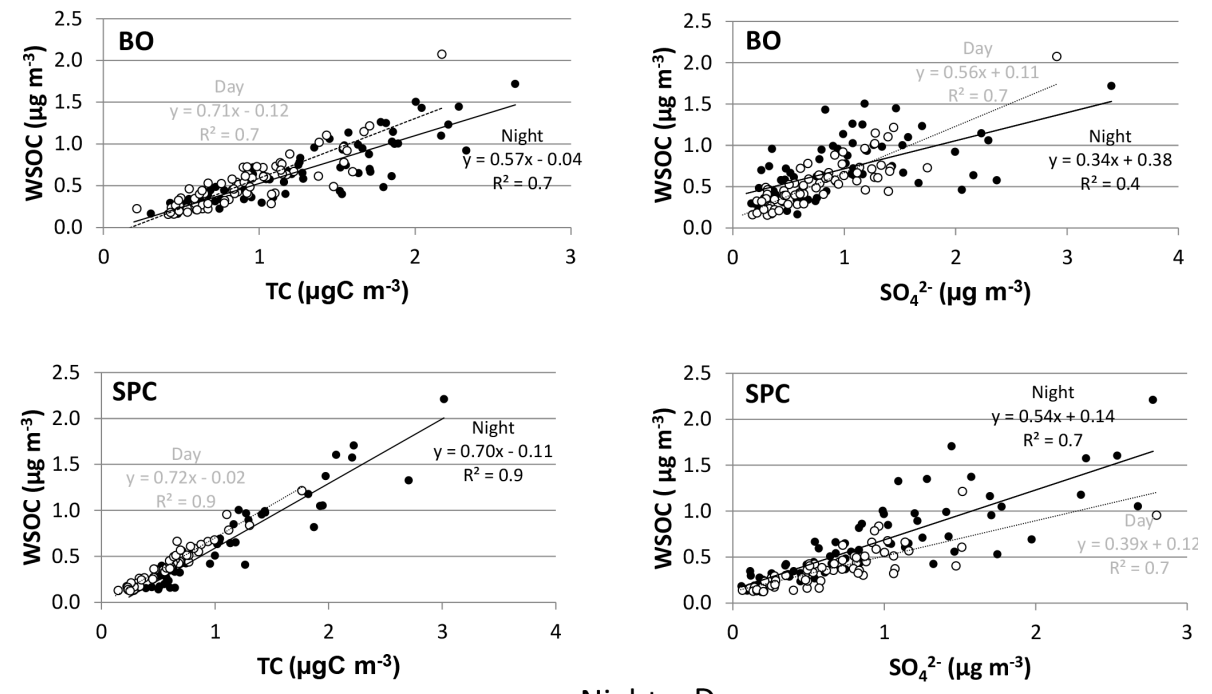

- Night $\circ$ Day

Figure 9. Linear regressions between WSOC and TC (left) and WSOC and $\mathrm{SO}_{4}^{2-}$ (right) in the size intervals: (1) 0.05-0.14 $\mu \mathrm{m},(2) 0.14-$ $0.42 \mu \mathrm{m}$ and (3) $0.42-1.2 \mu \mathrm{m}$ in daytime and at night for BO (top) and SPC (bottom).

at night in SPC and in similar proportions between WSOC and WINC, thus producing an aerosol with different characteristics in SPC with respect to BO.

The correlation of WSOC with a nonvolatile SIA component (sulfate) in $\mathrm{PM}_{1.2}$ is shown in the right panels of Fig. 9. A good correlation $\left(R^{2}=0.7\right)$ was observed at both stations in daytime, suggesting that WSOC shared a photochemical source with sulfate. The correlation in $\mathrm{BO}$ was much smaller at nighttime $\left(R^{2}=0.4\right)$ than in daytime, which is expected because particulate organic compounds have multiple sources other than photochemistry. Interestingly, the correlation between WSOC and sulfate remained high (0.7) at night in SPC, pointing to a common nocturnal source for WSOC and sulfate at the rural site.

Figure 10 shows, for the two sites, the size-resolved concentration time series of WSOC and WINC for quasiultrafine mode $(0.05-0.14 \mu \mathrm{m})$, condensation-mode $(0.14$ $0.42 \mu \mathrm{m})$ and droplet-mode $(0.42-1.2 \mu \mathrm{m})$ particles. The quasi-ultrafine fraction provided the smallest contribution to aerosol mass, but with significantly higher concentrations at the urban compared to the rural site for both WSOC and WINC. This feature was observed also in previous studies (Sardar et al., 2005; Snyder et al., 2010; Zhang et al., 2012). The urban excess of WINC witnesses the effect of local emissions of insoluble primary carbonaceous particles. On average, WSOC accounted for $52 \%$ of quasi-ultrafine TC in SPC and only $42 \%$ in BO, with the lower WSOC fraction at the urban site caused by the higher concentrations of WINC. An urban increment for WSOC in quasi-ultrafine particles can be observed, although smaller than for WINC, and can be explained by local sources of fresh SOA and by condensation on a greater number of ultrafine particles. WINC in this size range displayed nocturnal excess compared to WSOC, particularly in BO, without a clear relation with the trajectory lengths. We argue that the nocturnal peaks in quasi-ultrafine WINC concentrations could be related to the morning traffic rush hours, which, during the summer, had a maximum at 08:00-09:00, before the breakup of the nocturnal boundary layer and were therefore included in the nocturnal sampling periods. The evening traffic rush time between 19:00 and 20:00 had apparently a minor effect since it occurred while the boundary layer was still well mixed.

The distribution of carbonaceous fractions in the accumulation mode (condensation and droplet modes) showed that WSOC was in general dominant over WINC, more at the rural than at the urban site. The average WSOC/ TC ratio in the condensation mode was $65 \%$ in SPC and $60 \%$ in BO, while showing a greater difference between the two stations in the droplet mode (66\% in SPC and 56\% in BO). The WSOC concentrations were inversely related to trajectory length, indicating an effect of stagnation on oxidized organic aerosol production. Interestingly, the increase of WSOC levels during the stagnation periods did not affect the same size fractions to the same extent at the two sites. During the first episode, the maximum daytime WSOC concentration in the condensation mode, recorded on 19 June, corresponded to a $185 \%$ increase in BO and $150 \%$ in SPC compared to 15 June, the last day under the influence of North Atlantic circulation before the onset of the local recirculation. The enhancement of WSOC in daytime for droplet-mode particles amounted to $150 \%$ in BO and $195 \%$ in SPC. Therefore, the accumulation of water-soluble organic compounds occurred approximately to the same extent at the two sites in daytime, but the increase was more marked in droplet-mode 

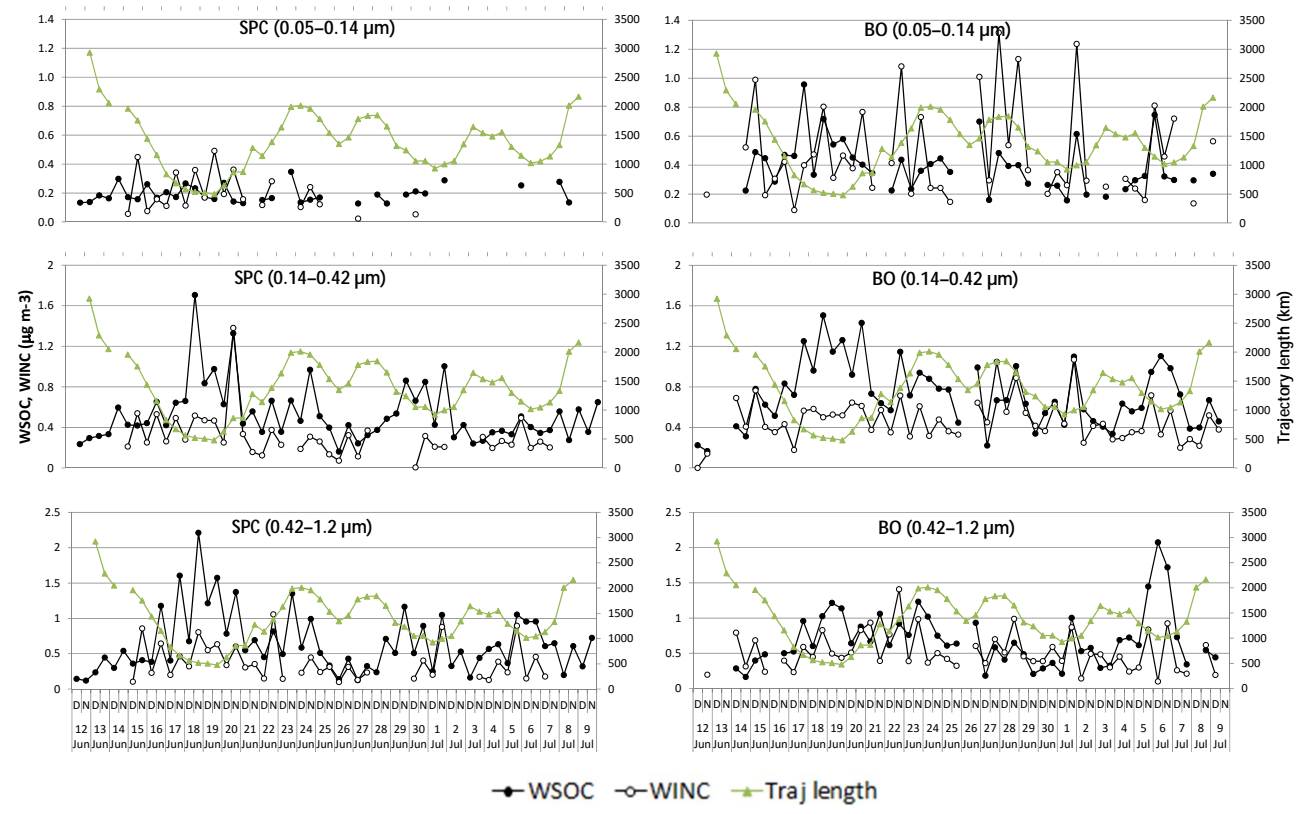

Figure 10. Time series of WSOC and WINC (= TC-WSOC) concentrations in the size intervals: (1) $0.05-0.14 \mu \mathrm{m},(2) 0.14-0.42 \mu \mathrm{m}$ and (3) $0.42-1.2 \mu \mathrm{m}$. Four-day back-trajectory length is superimposed to each graph. Results for the urban (BO) and for the rural (SPC) station are shown.

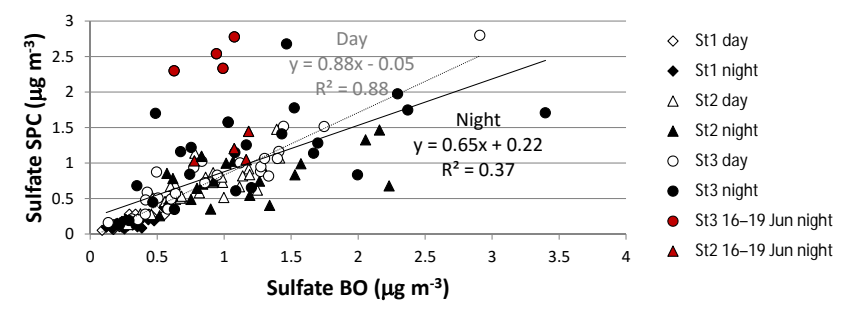

Figure 11. Scatterplot of sulfate concentration at SPC vs. BO during day and night for the impactor stages $1(0.05-0.14 \mu \mathrm{m}), 2(0.14$ $0.42 \mu \mathrm{m})$ and $3(0.42-1.2 \mu \mathrm{m})$. The regression lines are referred to the diurnal (gray line) and nocturnal (black line) concentrations in the three stages as a whole. Condensation- and droplet-mode samples for the stagnant nights during 16-19 June are filled in red.

particles in SPC and in the condensation mode in BO. The maximum nocturnal WSOC concentration, found on 18 June, corresponded to an enhancement in the condensation mode of 140 and $325 \%$ in BO and SPC, respectively, with respect to the background conditions of 15 June. The same increase in the droplet mode amounted to 115 (BO) and $440 \%$ (SPC). Therefore, the change in WSOC concentrations between background and stagnating conditions was more heterogeneous between sites for nocturnal samples than for the diurnal ones, which is expected because the atmosphere is much more stratified at night and atmospheric composition at ground level is more impacted by local conditions. In this case, a nocturnal enhancement of WSOC concentrations dur- ing the first stagnation period occurred only in SPC, with a maximum in the droplet mode.

During the second stagnant period, on 5-6 July, WSOC increased considerably in daytime in $\mathrm{BO}$ in both size ranges, while only a small increase was observed in SPC and limited to the droplet mode.

The behavior of accumulation-mode WSOC after the onset of stagnating conditions was therefore reversed during the (short) July event with respect to the first episode of 1620 June, with a marked increase in the droplet mode occurring in BO in July while interesting the SPC site in June (especially at night). The days (and nights) of maximum increase of droplet-mode WSOC were in fact those showing the highest submicron nitrate concentrations and were always humid days (or nights). Figure $8 \mathrm{~d}$ shows that WSOC was positively correlated with ALWC only in the droplet mode and only in SPC. The lack of correlation for BO samples can be explained by the very short duration of the humid stagnation period in July. Clearly, the increase of WSOC in droplet-mode aerosols in the stagnation periods was not homogeneous in the Po Valley and was associated locally to the presence of deliquesced particles. These findings indicate that the enrichment of WSOC was contributed by aqueous processes, including condensation in the aerosol liquid water, which were active preferentially during colder nighttime hours. Figure 8c and d also show that the behavior of WSOC reflects that of sulfate in SPC for droplet-mode aerosols, which explains the good correlation between WSOC and sulfate for nighttime samples observed only at the rural site where ALWC was high (Fig. 9 right panels). 


\subsection{Principal component analysis}

In the previous section, we focused on the time trends and size distributions of major carbonaceous and inorganic ionic species and we concluded that at least two secondary formation processes were active in the Po Valley: the first, probably photochemical, is active throughout the campaign at both stations, affecting the concentrations of all species and particularly in the condensation mode during stagnation periods; the second one is associated with deliquesced particles and is selectively important for nitrate (both condensation and droplet mode) and to a lesser extent for sulfate and WSOC in droplet-mode particles. In this section, we will extract source information from all the chemical datasets and from ancillary information. PCA was used to analyze the variability of the main variables of interest (the concentration of main SIAs and WSOC) in conjunction with the variability of the concentrations of minor species and tracers as well as of the physical parameters of the atmosphere. Six principal components were retained for interpretation of the SPC and BO datasets, explaining, respectively, 79 and $77 \%$ of the total variance. Increasing the number of factors progressively raises the explained variance, but each additional factor contributes only a small fractional increase and interpretation of the additional factors is also challenging. For the above reasons, a six-factor solution was chosen as the best one. The results of the PCA are summarized in Table 2 as factor loadings, which represent the correlation of each variable with each factor and hence suggest possible sources, formation mechanisms and source regions. For better clarity, loadings with absolute values below $0.2(|x| \leq 0.2)$ were omitted and only those with absolute values larger than $0.6(|x| \geq 0.6)$ were considered "high" (in bold in the table).

The first rotated component (RC1) explained the largest fraction of the dataset variance (22\%) in SPC. It involved high loadings of nitrate and ammonium for all the size classes. Among the meteorological parameters, the factor was strongly positively correlated with RH (0.82) and negatively with temperature $(-0.85)$. Thus $\mathrm{RC} 1$ describes the local meteorology and the nighttime condensation of ammonium nitrate in large accumulation-mode particles $(0.42-1.2 \mu \mathrm{m})$. Ammonium nitrate condensation in SPC was moderately positively correlated with droplet-mode sulfate, WSOC and oxalate, compounds (sulfate and oxalate) that share a source in aqueous secondary formation processes. A similar source was identified in the Bologna dataset in RC6 which, compared to SPC, explained only a smaller fraction $(9 \%)$ of the total variance. The relationship with temperature and RH was weaker in BO than in SPC, though in the same direction, and no clear relation was observed with dropletmode WSOC and sulfate.

RC2 was the second-most important factor in SPC, explaining $15 \%$ of the total variance in the dataset. Sulfate, oxalate, ammonium and WSOC were the species which correlated most with this factor, especially in the small $(0.14$
$0.42 \mu \mathrm{m})$ and large $(0.42-1.2 \mu \mathrm{m})$ accumulation mode. This factor was positively correlated with the sun flux integrated along the air-mass trajectory. This factor can therefore account for SIA and SOA photochemical production. An analogous factor in $\mathrm{BO}(\mathrm{RC} 2)$ explained a similar contribution to the total variance (17\%). A positive correlation (0.6) with $\mathrm{RH}$ was observed in BO, which was not significant in SPC. The significant contribution represented by this source on the total variance described for the two datasets highlights the importance of regional-scale secondary aerosol formation processes for the Po Valley environment.

The third factor in SPC is RC3, accounting for $14 \%$ of the total variance. This rotated component showed high loadings particularly for $\mathrm{Ca}^{2+}$ but also for $\mathrm{Mg}^{2+}$ in size bins 3 to 5 , corresponding to particles from 0.42 to $10 \mu \mathrm{m}$. Oxalate also showed a significant loading in size bin 5 $(3.5-10 \mu \mathrm{m})$, which suggested the uptake of gas-phase carboxylic acids by mineral particles, in agreement with past observations (Laongsri and Harrison, 2013; van Pinxteren et al., 2014). This factor is analogous to RC4 in the BO dataset, which explains $11 \%$ of the total variance, and was attributed to road dust resuspension. High loadings in $\mathrm{BO}$ were shifted toward larger diameters of particles (1.2 to $10 \mu \mathrm{m}$ ).

The fourth rotated component in SPC (RC4), which explained another $12 \%$ of the total variance, displayed the highest loadings for magnesium in coarse-mode particles and sodium in size bins 3 to 5 (from 0.42 to $10 \mu \mathrm{m}$ ). Sulfate in size bin $5(3.5-10 \mu \mathrm{m})$ was also moderately correlated with this factor, and nitrate too, but to a lesser extent. This factor can be interpreted as a contribution from sea salt components. The corresponding rotated component in $\mathrm{BO}$ was $\mathrm{RC} 1$, which explained $19 \%$ of the total variance and, compared to SPC, displayed higher loadings for sulfate and nitrate in size bin 4 (1.2 to $3.5 \mu \mathrm{m})$.

The fifth rotated component (RC5) in SPC, explaining $8 \%$ of the total variability, only included high loadings for RTIs, without any relevant correlation with other parameters. This factor was identified both in SPC and in BO (RC5), explaining, respectively, 8 and $10 \%$ of the total variance. While this factor does not represent an aerosol source, it indicates that during this campaign the impact of air-mass history (longrange transport) was likely small as compared to other impacts such as day/night variability or local impacts.

Finally, the last rotated component, which explained an additional $8 \%$ of the total variance in SPC (RC6) and $11 \%$ in $\mathrm{BO}$ (RC3), contained high loadings only in the first size range $(0.05-0.14 \mu \mathrm{m})$ for sulfate, ammonium and to a lesser extent WSOC. The significant loading of sulfate and ammonium in quasi-ultrafine particles, together with a moderate positive correlation with solar radiation and temperature, suggests a possible source for this component in ultrafine particle nucleation. The role of these chemical species in the formation of new particles and their condensation/coagulation on smaller particulate matter are well known, as is the influence of solar radiation on this aerosol 
Table 2. Factor loadings of PCA after Varimax rotation. Only absolute values larger than 0.2 are shown. Absolute values larger than 0.60 are considered significant and printed in bold. The number beside each chemical species in the first column indicates the impactor stage.

\begin{tabular}{|c|c|c|c|c|c|c|c|c|c|c|c|c|}
\hline \multirow{2}{*}{$\begin{array}{l}\text { Site } \\
\text { Rotated component } \\
\text { Assigned } \\
\text { source }\end{array}$} & \multicolumn{6}{|c|}{ SPC } & \multicolumn{6}{|c|}{$\mathrm{BO}$} \\
\hline & $\begin{array}{r}\mathrm{RC} 1 \\
\text { Conden- } \\
\text { sation }\end{array}$ & $\begin{array}{r}\text { RC2 } \\
\text { Photochem. } \\
\text { SIA + } \\
\text { SOA }\end{array}$ & $\begin{array}{l}\text { RC3 } \\
\text { Dust }\end{array}$ & $\begin{array}{r}\text { RC4 } \\
\text { Sea } \\
\text { salt }\end{array}$ & $\begin{array}{r}\text { RC5 } \\
\text { RTI } \\
\text { var. }\end{array}$ & $\begin{array}{r}\text { RC6 } \\
\text { gasSIA + } \\
\text { gasSOA }\end{array}$ & $\begin{array}{r}\text { RC1 } \\
\text { Sea } \\
\text { salt }\end{array}$ & $\begin{array}{r}\text { RC2 } \\
\text { Photochem. } \\
\text { SIA + } \\
\text { SOA }\end{array}$ & $\begin{array}{r}\mathrm{RC} 3 \\
\text { gasSIA + } \\
\text { gasSOA }\end{array}$ & $\begin{array}{r}\text { RC4 } \\
\text { Resusp. }\end{array}$ & $\begin{array}{c}\text { RC5 } \\
\text { RTI } \\
\text { var. }\end{array}$ & $\begin{array}{r}\text { RC6 } \\
\text { Conden- } \\
\text { sation }\end{array}$ \\
\hline Nitrate_1 & 0.81 & & & -0.24 & 0.24 & & & & & & & 0.69 \\
\hline Sulfate_1 & -0.32 & 0.28 & & & & 0.79 & & 0.26 & 0.84 & & & \\
\hline Oxalate_1 & -0.34 & & 0.25 & -0.24 & 0.45 & 0.37 & -0.53 & 0.24 & 0.42 & & & \\
\hline Ammonium_1 & & 0.21 & & & 0.23 & 0.84 & & & 0.79 & & 0.29 & \\
\hline WSOC_1 & & 0.23 & 0.35 & -0.40 & 0.29 & 0.46 & -0.45 & 0.37 & 0.41 & 0.30 & 0.38 & \\
\hline Nitrate_2 & 0.79 & 0.36 & & & & & & 0.28 & & & & 0.84 \\
\hline Sulfate_2 & & 0.83 & & 0.30 & & & 0.42 & 0.75 & 0.22 & & & \\
\hline Oxalate_2 & 0.28 & 0.81 & 0.31 & -0.22 & & & & 0.71 & 0.43 & & & 0.34 \\
\hline Sodium_2 & & & & 0.25 & -0.23 & 0.33 & 0.43 & -0.21 & 0.56 & 0.23 & -0.29 & \\
\hline Ammonium_2 & 0.56 & 0.69 & & & & 0.24 & 0.39 & 0.77 & & & & 0.38 \\
\hline WSOC_2 & 0.30 & 0.71 & 0.46 & & & & & 0.72 & 0.43 & & & 0.30 \\
\hline Nitrate_3 & 0.82 & 0.40 & & & & & 0.21 & 0.36 & -0.25 & & & 0.78 \\
\hline Sulfate_3 & 0.36 & 0.79 & & & & & 0.32 & 0.86 & & & & \\
\hline Oxalate_3 & 0.45 & 0.73 & 0.32 & & & & & 0.76 & & & & \\
\hline Sodium_3 & -0.27 & & 0.21 & 0.84 & & & 0.87 & & & & & \\
\hline Ammonium_3 & 0.67 & 0.67 & & & & & 0.29 & 0.81 & & & & 0.32 \\
\hline Magnesium_3 & -0.24 & 0.22 & 0.80 & 0.33 & & & 0.62 & & 0.24 & 0.42 & & 0.28 \\
\hline Calcium_3 & & & 0.92 & & & & & & & 0.50 & -0.37 & 0.27 \\
\hline WSOC_3 & 0.50 & 0.75 & 0.32 & & & & & 0.86 & & & & 0.23 \\
\hline Chloride_4 & 0.57 & & & 0.32 & & -0.29 & 0.51 & 0.22 & -0.45 & & & 0.31 \\
\hline Nitrate_4 & 0.82 & & & 0.43 & & & 0.79 & 0.28 & & 0.28 & & 0.33 \\
\hline Sulfate_4 & 0.69 & 0.32 & & 0.39 & -0.23 & & 0.75 & 0.45 & & 0.24 & -0.30 & \\
\hline Oxalate_4 & & 0.50 & 0.35 & 0.38 & -0.23 & & 0.31 & 0.24 & 0.24 & 0.36 & -0.37 & \\
\hline Sodium_4 & & & & 0.94 & & & 0.90 & & -0.21 & & & \\
\hline Ammonium_4 & 0.89 & 0.27 & & & & & 0.34 & 0.30 & & 0.24 & & 0.70 \\
\hline Magnesium_4 & & & 0.57 & 0.77 & & & 0.88 & 0.21 & & 0.29 & & \\
\hline Calcium_4 & & & 0.93 & & & & 0.41 & & & 0.64 & -0.28 & 0.29 \\
\hline WSOC_4 & 0.47 & 0.31 & 0.52 & & & & & 0.67 & & 0.42 & & -0.28 \\
\hline Chloride_5 & 0.57 & 0.29 & & 0.23 & & & 0.47 & & -0.66 & 0.26 & & \\
\hline Nitrate_5 & 0.56 & 0.37 & 0.37 & 0.46 & & & 0.54 & & & 0.65 & & \\
\hline Sulfate_5 & 0.47 & & 0.33 & 0.64 & -0.30 & & 0.69 & & & 0.60 & -0.22 & \\
\hline Oxalate_5 & & 0.29 & 0.64 & 0.21 & & & & 0.29 & & 0.55 & -0.46 & \\
\hline Sodium_5 & & -0.23 & & 0.75 & & & 0.71 & & -0.50 & 0.32 & & \\
\hline Ammonium_5 & 0.80 & 0.29 & & & & 0.26 & & 0.23 & & 0.54 & & 0.50 \\
\hline Magnesium_5 & 0.29 & & 0.60 & 0.66 & & & 0.69 & & -0.31 & 0.56 & & \\
\hline Calcium_5 & & & 0.87 & & & 0.24 & 0.33 & & & 0.89 & & \\
\hline WSOC_ $\_\overline{5}$ & 0.32 & 0.30 & 0.65 & 0.21 & & & & 0.48 & & 0.55 & & -0.27 \\
\hline RT_waterandice & & & & & -0.95 & & & & & & -0.93 & \\
\hline RT_naturalveg & & & & & 0.70 & -0.47 & & & & & 0.82 & -0.21 \\
\hline RT_agriculture & & & & & 0.81 & 0.39 & -0.33 & & & & 0.84 & \\
\hline RT_urbanareas & & & & & 0.90 & & & & & & 0.91 & \\
\hline RT_bareareas & 0.43 & & & & & 0.64 & -0.53 & & & 0.29 & & 0.25 \\
\hline Sunflux_alongtraj & & 0.68 & & & & 0.50 & -0.22 & 0.24 & 0.68 & & -0.25 & \\
\hline Temperature & -0.85 & & & & & 0.30 & & -0.29 & 0.69 & & -0.26 & -0.23 \\
\hline $\mathrm{RH}$ & 0.82 & & & & & -0.31 & & 0.60 & -0.49 & & & 0.34 \\
\hline Explained variance (\%) & 22 & 15 & 14 & 12 & 8 & 8 & 19 & 17 & 11 & 11 & 10 & 9 \\
\hline Cumulative variance $(\%)$ & 22 & 37 & 51 & 63 & 71 & 79 & 19 & 36 & 47 & 58 & 68 & 77 \\
\hline
\end{tabular}

generation process (Hamed et al., 2010). The negative relation with RH confirmed that this source was active during the day, when RH was at minimum.

In summary, the PCA analysis provides a synthetic analysis of the main sources of variability in the chemical dataset, but it is not intended to resolve all of them. It should be noticed, for instance, that the five factors in $\mathrm{BO}$ do not recover the local sources of small carbonaceous particles (Fig. 10) which increase at night at the urban site, lowering the nocturnal correlation between WSOC and sulfate (Fig. 9).

\section{Discussion and conclusions}

The PCA results indicate that several factors determined the variability in the size-segregated chemical composition in the region during the PEGASOS Po Valley field campaign, but each of them affected preferentially specific size intervals with an overall effect of shaping the aerosol mass distribution at the two sites. Two factors corresponding to sea salt and mineral dust with absorbed nitrate regulated the concentrations and composition of coarse particles $\left(\mathrm{PM}_{1.2-10}\right)$, while only one factor was found to determine an enrich- 
ment of ammonium sulfate in the quasi-ultrafine range. Finally, the variability in composition of accumulation-mode aerosol could be reduced to two factors, with one related to regional-scale photochemical formation of SOA and SIA and a second one more dependent on local conditions at surface level and causing a nocturnal increase of SOA and SIA in the droplet mode. However, when the factor for photochemical secondary aerosols was equally represented at the two sites, the other one (for nighttime condensation) was much more important at the rural station (SPC) than in BO. The effect on a simple nonvolatile SIA component, sulfate, is exemplified in the scatter plot in Fig. 11. A good correlation $\left(R^{2}=0.9\right)$ was indeed observed between the accumulation-mode sulfate concentrations at the two sites in daytime (Fig. 11), with only a slight dilution $(-12 \%)$ of the concentrations at the background site with respect to the urban site, which is expected for an aerosol component that is typically associated with regional-scale photochemical pollution. By contrast, the correlation between the concentration trends at the two sites is much lower at night, especially as regards the droplet mode, when significantly higher sulfate concentrations occurred in SPC compared to BO during the stagnant period from 16 to 20 June. Clearly, stagnating conditions and the onset of thermal inversions at night favored a partial "chemical segregation" of air masses in the surface atmospheric layers within the Po Valley, and the size-segregated chemical composition evolved separately at the urban sites close to the Apennine foothills with respect to the rural areas in the inner Po Valley during dark hours. Specifically, rural areas were characterized by the presence of ammonium nitrate and by ALWC levels above $10 \mu \mathrm{g} \mathrm{m}^{-3}$. Deliquesced aerosols could host aqueous-phase formation of sulfate (via reaction of $\mathrm{SO}_{2}$ with $\mathrm{H}_{2} \mathrm{O}_{2}$ ).

Similarly to SIAs in the droplet mode, water-soluble products of volatile organic compound (VOC) oxidation could readily be taken up by deliquesced particles in SPC at night. A meaningful fraction of the newly formed (1-3h old) WSOC mass, in fact, has been shown to possess similar semi-volatile properties to $\mathrm{NH}_{4} \mathrm{NO}_{3}$ (Hennigan et al., 2008; Wilson et al., 2006) and can rapidly partition to aerosol water or cloud/fog droplets. The nature of the nocturnal enrichment of WSOC in the droplet mode, depending on the reactivity in the aqueous phase, can be described by either a reversible mechanism (condensation of watersoluble organic compounds triggered by the change in $\mathrm{RH}$ and ALWC) or an irreversible reaction (oxidation of VOCs or oxygenated VOCs with production of stable compounds). Hodas et al. (2014), based on measurements performed during the same campaign in SPC, observed an exponential decrease in gas-phase glyoxal concentrations with increasing ALWC, and a local nocturnal production of aqueous SOA was indeed observed by parallel near-real-time WSOC sampled with a particle into liquid sampler (PILS) at the same site (Sullivan et al., 2016). The analysis of impactor samples provides only a few clues to disentangle the two effects.
The only two organic markers for SOA that were quantitatively determined in all samples were oxalate and MSA. The robust correlation between WSOC, oxalate and sulfate, both in daytime and at nighttime in SPC, indicates that the accumulation of particulate polar organic compounds contributed to the (irreversible) production of stable (oxidized) species. Oxalate is generally known to share with sulfate an important aqueous-phase oxidation pathway (Sorooshian et al., 2006). MSA is a more specific marker than oxalate, being related to the atmospheric processing of dimethyl sulfide (DMS) whose emissions are unevenly distributed on the Earth surface, and can be intense in biogenically rich marine waters. Our data indeed showed that fine-mode MSA was maximum in the days between 26 June and 1 July, characterized by an easterly or a south-southwesterly circulation, bringing marine air masses into the Po Valley basin. Such increase from long-range transport affected particularly the size intervals $0.05-0.14 \mu \mathrm{m}$ and $0.14-0.42 \mu \mathrm{m}$. MSA concentrations in the droplet mode $(0.42-1.2 \mu \mathrm{m})$ showed instead an enhancement at night under stagnant conditions, similarly to ammonium nitrate (see Supplement), particularly marked in SPC during both episodes and in BO only during 5-6 July. The increase of MSA in droplet-mode particles under stagnating conditions points to a DMS (or other reduced sulfur species) source other than from the marine boundary layer. In inland areas DMS has sometimes been reported as dominantly from terrestrial sources (vegetation and soils) and anthropogenic sources (manure and livestock), with higher temperatures and solar radiation enhancing its emission (Perraud et al., 2015). These findings suggest that the VOCs participating to the formation of WSOC in the Po Valley also included organic compounds emitted by agricultural activities or even by natural sources and that ALWC in the atmospheric nocturnal surface layer acted as a medium for their formation during summer time.

In conclusion, the characteristics of the size-segregated aerosol composition and its variability at a rural and an urban background site in the Po Valley could be explained by a limited number of factors reflecting main physicochemical processes and/or transport patterns in the atmosphere. For accumulation-mode particles in particular, our analysis points to two main processes. (1) The first is the photochemical production of SIA and SOA, which occur at comparable concentrations at the two sites; this process is particularly evident in daytime hours when the lower atmosphere is well mixed, indicating that a major fraction of background submicron aerosol concentrations in the Po Valley actually originates from regional-scale sources, which can extend over vast continental areas (see also Fig. S12 in Decesari et al., 2014). This has implications for air quality mitigation because this photochemical component is expected to show little sensitivity to local-scale (city-level) regulations. (2) The second is nocturnal SIA and SOA formation, enhanced in the shallow, cool and humid boundary layer and favored by the presence of aerosol liquid water. Such component of the rural 
background aerosol appears more volatile (hence labile) and more heterogeneously distributed across the Po Valley, with the inner part (where most agricultural activity occurs) acting as a source region, especially in terms of agricultural $\mathrm{NH}_{3}$ emissions, with respect to its southern periphery (more urbanized). The rural background concentration level is therefore variable, with a positive gradient from the Apennines border to the central valley, at least for half of the day. These results represent an example of a limitation of the classical Lenschow model.

\section{Data availability}

Data are available on request by contacting the corresponding author by e-mail.

\section{The Supplement related to this article is available online at doi:10.5194/acp-16-10879-2016-supplement.}

Acknowledgements. This research was conducted as part of the "Supersito" Project, supported by Emilia Romagna Region and Regional Agency for Prevention and Environment (ARPA Emilia Romagna) under Deliberation Regional Government n. 428/10. The work was also made possible by the European Commission under the Framework Programme 7 (FP7) projects PEGASOS (grant agreement 265148), BACCHUS (grant agreement 603445) and by the CNR Joint Lab Project Air-Sea Lab, which are highly acknowledged.

Edited by: E. Nemitz

Reviewed by: two anonymous referees

\section{References}

Bertram, T. H., Thornton, J. A., Riedel, T. P., Middlebrook, A. M., Bahreini, R., Bates, T. S., Quinn, P. K., and Coffman, D. J.: Direct observations of $\mathrm{N}_{2} \mathrm{O}_{5}$ reactivity on ambient aerosol particles, Geophys. Res. Lett., 36, L19803, doi:10.1029/2009g1040248, 2009

Bucci, S., Cairo, F., Cristofanelli, P., Decesari, S., Groess, J., and Fierli, F.: Transport regimes analysis over the Po Valley during summer 2012: impacts on Planetary Boundary Layer variability and aerosol content, in preparation, 2016.

Carbone, C., Decesari, S., Mircea, M., Giulianelli, L., Finessi, E., Rinaldi, M., Fuzzi, S., Marinoni, A., Duchi, R., Perrino, C., Sargolini, T., Varde, M., Sprovieri, F., Gobbi, G. P., Angelini, F., and Facchini, M. C.: Size-resolved aerosol chemical composition over the Italian Peninsula during typical summer and winter conditions, Atmos. Environ., 44, 5269-5278, 2010.

Clegg, S. L., Brimblecombe, P., and Wexler, A. S.: Thermodynamic model of the system $\mathrm{H}^{+}-\mathrm{NH}_{4}^{+}-\mathrm{SO}_{4}^{2-}-\mathrm{NO}_{3}^{-}-\mathrm{H}_{2} \mathrm{O}$ at tropospheric temperatures, J. Phys. Chem. A, 102, 2137-2154, 1998.
Crosier, J., Allan, J. D., Coe, H., Bower, K. N., Formenti, P., and Williams, P. I.: Chemical composition of summertime aerosol in the Po Valley (Italy), northern Adriatic and Black Sea, Q. J. Roy. Meteor. Soc., 133, 61-75, 2007.

Decesari, S., Allan, J., Plass-Duelmer, C., Williams, B. J., Paglione, M., Facchini, M. C., O’Dowd, C., Harrison, R. M., Gietl, J. K., Coe, H., Giulianelli, L., Gobbi, G. P., Lanconelli, C., Carbone, C., Worsnop, D., Lambe, A. T., Ahern, A. T., Moretti, F., Tagliavini, E., Elste, T., Gilge, S., Zhang, Y., and Dall'Osto, M.: Measurements of the aerosol chemical composition and mixing state in the Po Valley using multiple spectroscopic techniques, Atmos. Chem. Phys., 14, 12109-12132, doi:10.5194/acp-1412109-2014, 2014.

Decesari, S., Facchini, M. C., Sandrini, S., Paglione, M., Gilardoni, S., Rinaldi, M., Cristofanelli, P., Cairo, F., Gobbi, G. P., Poluzzi, V., Morgillo, A., Bonafè, G., Mentel, T., Kindler-Schaar, A., Manninen, H., Poulain, L., Wolf, F., Baltensperger, U., Ganzeveld, L., Nemitz, E., and Pandis, S.: The 2012 PEGASOSSUPERSITO Po Valley campaign: an overview, in preparation, 2016.

Dorling, S. R., Davies, T. D., and Pierce, C. E.: Cluster Analysis A technique for estimating the synoptic meteorological controls on air and precipitation chemistry - Method and applications, Atmos. Enviro. A-Gen., 26, 2575-2581, 1992.

Draxler, R. R. and Rolph, G. D.: HYSPLIT (HYbrid Single-Particle Lagrangian Integrated Trajectory) Model access via NOAA ARL READY Website, available at: http://www.arl.noaa.gov/ready/ hysplit4.html, NOAA Air Resources Laboratory, Silver Spring, MD, 2003 (last access: September 2015).

Farnham, I. M., Singh, A. K., Stetzenbach, K. J., and Johannesson, K. H.: Treatment of nondetects in multivariate analysis of groundwater geochemistry data, Chemometr. Intell. Lab., 60, 265-281, 2002.

Gelencser, A., Meszaros, T., Blazso, M., Kiss, G., Krivacsy, Z., Molnar, A., and Meszaros, E.: Structural characterisation of organic matter in fine tropospheric aerosol by pyrolysis-gas chromatography-mass spectrometry, J. Atmos. Chem., 37, 173$183,2000$.

Gietl, J. K., Tritscher, T., and Klemm, O.: Size-segregated analysis of $\mathrm{PM}_{10}$ at two sites, urban and rural, in Munster (Germany) using five-stage Berner type impactors, Atmos. Environ., 42, 57215727, 2008.

Gilardoni, S., Massoli, P., Giulianelli, L., Rinaldi, M., Paglione, M., Pollini, F., Lanconelli, C., Poluzzi, V., Carbone, S., Hillamo, R., Russell, L. M., Facchini, M. C., and Fuzzi, S.: Fog scavenging of organic and inorganic aerosol in the Po Valley, Atmos. Chem. Phys., 14, 6967-6981, doi:10.5194/acp-14-6967-2014, 2014.

Hamed, A., Birmili, W., Joutsensaari, J., Mikkonen, S., Asmi, A., Wehner, B., Spindler, G., Jaatinen, A., Wiedensohler, A., Korhonen, H., Lehtinen, K. E. J., and Laaksonen, A.: Changes in the production rate of secondary aerosol particles in Central Europe in view of decreasing $\mathrm{SO}_{2}$ emissions between 1996 and 2006, Atmos. Chem. Phys., 10, 1071-1091, doi:10.5194/acp-10-10712010, 2010.

Harrison, R. M. and Pio, C. A.: Size-differentiated composition of inorganic atmospheric aerosols of both marine and polluted continental origin, Atmos. Environ., 17, 1733-1738, 1983.

Hennigan, C. J., Bergin, M. H., Dibb, J. E., and Weber, R. J.: Enhanced secondary organic aerosol formation due to wa- 
ter uptake by fine particles, Geophys. Res. Lett., 35, L18801, doi:10.1029/2008g1035046, 2008.

Hering, S. V. and Friedlander, S. K.: Origins of aerosol sulfur size distributions in the Los-Angeles Basin, Atmos. Environ., 16, 2647-2656, 1982.

Hodas, N., Sullivan, A. P., Skog, K., Keutsch, F. N., Collett, J. L., Decesari, S., Facchini, M. C., Carlton, A. G., Laaksonen, A., and Turpin, B. J.: Aerosol Liquid Water Driven by Anthropogenic Nitrate: Implications for Lifetimes of Water-Soluble Organic Gases and Potential for Secondary Organic Aerosol Formation, Environ. Sci. Technol., 48, 11127-11136, 2014.

Jimenez, J. L., Jayne, J. T., Shi, Q., Kolb, C. E., Worsnop, D. R., Yourshaw, I., Seinfeld, J. H., Flagan, R. C., Zhang, X. F., Smith, K. A., Morris, J. W., and Davidovits, P.: Ambient aerosol sampling using the Aerodyne Aerosol Mass Spectrometer, J. Geophys. Res.-Atmos., 108, 8425, doi:10.1029/2001jd001213, 2003.

John, W., Wall, S. M., Ondo, J. L., and Winklmayr, W.: Modes in the size distributions of atmospheric inorganic aerosol, Atmos. Environ. A-Gen., 24, 2349-2359, 1990.

Krivacsy, Z., Hoffer, A., Sarvari, Z., Temesi, D., Baltensperger, U., Nyeki, S., Weingartner, E., Kleefeld, S., and Jennings, S. G.: Role of organic and black carbon in the chemical composition of atmospheric aerosol at European background sites, Atmos. Environ., 35, 6231-6244, 2001.

Laongsri, B. and Harrison, R. M.: Atmospheric behaviour of particulate oxalate at UK urban background and rural sites, Atmos. Environ., 71, 319-326, 2013.

Laskin, A., Wietsma, T. W., Krueger, B. J., and Grassian, V. H.: Heterogeneous chemistry of individual mineral dust particles with nitric acid: A combined CCSEM/EDX, ESEM, and ICP-MS study, J. Geophys. Res.-Atmos., 110, D10208, doi:10.1029/2004jd005206, 2005.

Lenschow, P., Abraham, H. J., Kutzner, K., Lutz, M., Preuss, J. D., and Reichenbacher, W.: Some ideas about the sources of $\mathrm{PM}_{10}$, Atmos. Environ., 35, S23-S33, 2001.

Matta, E., Facchini, M. C., Decesari, S., Mircea, M., Cavalli, F., Fuzzi, S., Putaud, J.-P., and Dell'Acqua, A.: Mass closure on the chemical species in size-segregated atmospheric aerosol collected in an urban area of the Po Valley, Italy, Atmos. Chem. Phys., 3, 623-637, doi:10.5194/acp-3-623-2003, 2003.

Meng, Z. Y. and Seinfeld, J. H.: On the source of the submicrometer droplet mode of urban and regional aerosols, Aerosol Sci. Tech., 20, 253-265, 1994.

Perraud, V., Horne, J. R., Martinez, A. S., Kalinowski, J., Meinardi, S., Dawson, M. L., Wingen, L. M., Dabdub, D., Blake, D. R., Gerber, R. B., and Finlayson-Pitts, B. J.: The future of airborne sulfur-containing particles in the absence of fossil fuel sulfur dioxide emissions, P. Natl. Acad. Sci. USA, 112, 13514-13519, 2015.

Putaud, J. P., Van Dingenen, R., Alastuey, A., Bauer, H., Birmili, W., Cyrys, J., Flentje, H., Fuzzi, S., Gehrig, R., Hansson, H. C., Harrison, R. M., Herrmann, H., Hitzenberger, R., Hueglin, C., Jones, A. M., Kasper-Giebl, A., Kiss, G., Kousa, A., Kuhlbusch, T. A. J., Loeschau, G., Maenhaut, W., Molnar, A., Moreno, T., Pekkanen, J., Perrino, C., Pitz, M., Puxbaum, H., Querol, X., Rodriguez, S., Salma, I., Schwarz, J., Smolik, J., Schneider, J., Spindler, G., ten Brink, H., Tursic, J., Viana, M., Wiedensohler, A., and Raes, F.: A European aerosol phenomenology-3: Physical and chemical characteristics of particulate matter from 60 rural, urban, and kerbside sites across Europe, Atmos. Environ., 44, 1308-1320, 2010.

Sardar, S. B., Fine, P. M., and Sioutas, C.: Seasonal and spatial variability of the size-resolved chemical composition of particulate matter $\left(\mathrm{PM}_{10}\right)$ in the Los Angeles Basin, J. Geophys. Res.Atmos., 110, D07S08, doi:10.1029/2004jd004627, 2005.

Schaap, M., van Loon, M., ten Brink, H. M., Dentener, F. J., and Builtjes, P. J. H.: Secondary inorganic aerosol simulations for Europe with special attention to nitrate, Atmos. Chem. Phys., 4, 857-874, doi:10.5194/acp-4-857-2004, 2004.

Seinfeld, J. H. and Pandis, S. N. (Eds.): Atmospheric Chemistry and Physics, from Air Pollution to Climate Change, John Wiley and Sons, New York, 1998.

Snyder, D. C., Rutter, A. P., Worley, C., Olson, M., Plourde, A., Bader, R. C., Dallmann, T., and Schauer, J. J.: Spatial variability of carbonaceous aerosols and associated source tracers in two cites in the Midwestern United States, Atmos. Environ., 44, 1597-1608, 2010.

Sorooshian, A., Varutbangkul, V., Brechtel, F. J., Ervens, B., Feingold, G., Bahreini, R., Murphy, S. M., Holloway, J. S., Atlas, E. L., Buzorius, G., Jonsson, H., Flagan, R. C., and Seinfeld, J. H.: Oxalic acid in clear and cloudy atmospheres: Analysis of data from International Consortium for Atmospheric Research on Transport and Transformation 2004, J. Geophys. Res.-Atmos., 111, D23S45, doi:10.1029/2005jd006880, 2006.

Stelson, A. W. and Seinfeld, J. H.: Relative-humidity and temperature-dependence of the ammonium-nitrate dissociation constant, Atmos. Environ., 16, 983-992, 1982.

Sullivan, A. P., Hodas, N., Turpin, B. J., Skog, K., Keutsch, F. N., Gilardoni, S., Paglione, M., Rinaldi, M., Decesari, S., Facchini, M. C., Poulain, L., Herrmann, H., Wiedensohler, A., Nemitz, E., Twigg, M. M., and Collett Jr., J. L.: Evidence for ambient dark aqueous SOA formation in the Po Valley, Italy, Atmos. Chem. Phys., 16, 8095-8108, doi:10.5194/acp-16-8095-2016, 2016.

Vandeginste, B. G. M.: Data mining of water quality data by chemometrical methods, in: Monitoring of Water Quality: the Contribution of Advanced Technologies, Colin and Quevauviller, Elsevier, 49-53, doi:10.1016/b978-008043340-0/50005-9, 1998.

van Pinxteren, D., Brueggemann, E., Gnauk, T., Mueller, K., Thiel, C., and Herrmann, H.: A GIS based approach to back trajectory analysis for the source apportionment of aerosol constituents and its first application, J. Atmos. Chem., 67, 1-28, 2010.

van Pinxteren, D., Neusüß, C., and Herrmann, H.: On the abundance and source contributions of dicarboxylic acids in sizeresolved aerosol particles at continental sites in central Europe, Atmos. Chem. Phys., 14, 3913-3928, doi:10.5194/acp-14-39132014, 2014.

Watson, J. G., Chow, J. C., Lurmann, F. W., and Musarra, S. P.: Ammonium-nitrate, nitric-acid, and ammonia equilibrium in wintertime Phoenix, Arizona, J. Air Waste Manage., 44, 405412, 1994.

Weber, R. J., Sullivan, A. P., Peltier, R. E., Russell, A., Yan, B., Zheng, M., de Gouw, J., Warneke, C., Brock, C., Holloway, J. S., Atlas, E. L., and Edgerton, E.: A study of secondary organic aerosol formation in the anthropogenic-influenced southeastern United States, J. Geophys. Res.-Atmos., 112, D13302, doi:10.1029/2007jd008408, 2007.

Westerdahl, D., Fruin, S., Sax, T., Fine, P. M., and Sioutas, C.: Mobile platform measurements of ultrafine particles and associated 
pollutant concentrations on freeways and residential streets in Los Angeles, Atmos. Environ., 39, 3597-3610, 2005.

Wexler, A. S. and Clegg, S. L.: Atmospheric aerosol models for systems including the ions $\mathrm{H}^{+}, \mathrm{NH}_{4}^{+}, \mathrm{Na}^{+}, \mathrm{SO}_{4}^{2-}$, $\mathrm{NO}_{3}^{-}, \mathrm{Cl}^{-}, \mathrm{Br}^{-}$, and $\mathrm{H}_{2} \mathrm{O}$, J. Geophys. Res.-Atmos., 107, doi:10.1029/2001jd000451, 2002.

Wilson, W. E., Grover, B. D., Long, R. W., Eatough, N. L., and Eatough, D. J.: The measurement of fine-particulate semivolatile material in urban aerosols, J. Air Waste Manage., 56, 384-397, 2006.

Wolf, R., El Haddad, I., Crippa, M., Decesari, S., Slowik, J. G., Poulain, L., Gilardoni, S., Rinaldi, M., Carbone, S., Canonaco, F., Huang, R. J., Baltensperger, U., and Prevot, A. S. H.: Marine and urban influences on summertime $\mathrm{PM}_{2.5}$ aerosol in the Po basin using mobile measurements, Atmos. Environ., 120, 447$454,2015$.
Zappoli, S., Andracchio, A., Fuzzi, S., Facchini, M. C., Gelencser, A., Kiss, G., Krivacsy, Z., Molnar, A., Meszaros, E., Hansson, H. C., Rosman, K., and Zebuhr, Y.: Inorganic, organic and macromolecular components of fine aerosol in different areas of Europe in relation to their water solubility, Atmos. Environ., 33, 2733 2743, 1999.

Zhang, X., Liu, Z., Hecobian, A., Zheng, M., Frank, N. H., Edgerton, E. S., and Weber, R. J.: Spatial and seasonal variations of fine particle water-soluble organic carbon (WSOC) over the southeastern United States: implications for secondary organic aerosol formation, Atmos. Chem. Phys., 12, 6593-6607, doi:10.5194/acp-12-6593-2012, 2012. 